\title{
Evaluation of the Wind Energy Potential in the Coastal Environment of Two Enclosed Seas
}

\author{
Florin Onea, Alina Raileanu, and Eugen Rusu \\ Department of Mechanical Engineering, “Dunarea de Jos” University of Galati, 6200 Galati, Romania \\ Correspondence should be addressed to Eugen Rusu; erusu@ugal.ro
}

Received 1 April 2015; Revised 29 May 2015; Accepted 30 May 2015

Academic Editor: Julio Diaz

Copyright (C) 2015 Florin Onea et al. This is an open access article distributed under the Creative Commons Attribution License, which permits unrestricted use, distribution, and reproduction in any medium, provided the original work is properly cited.

The work presents a comprehensive picture of the wind energy potential in the coastal environment of the Black and the Caspian Seas. 10-year of data coming from the US National Centers for Environmental Prediction was considered as the main source. This dataset was subsequently compared with both in situ and remotely sensed measurements. The results show that the western side of the Black Sea has an enhanced wind power potential, especially in the vicinity of the Crimean Peninsula. As regards the Caspian Sea, the northeastern sector can be considered more energetic. A direct comparison of various wind parameters corresponding to the locations with higher potential in the two target areas considered was also carried out, in order to notice the similarities and the key features that could be taken into account in the development of an offshore wind project. Finally, it can be concluded that the coastal environments of the Black and the Caspian Seas can become in the near future promising locations for the wind energy extraction, as well as for the hybrid wind-wave energy farms that could play an important role also in the coastal protection.

\section{Introduction}

The present work is focused on two enclosed seas, the Black and the Caspian Seas, and it has as main objective to assess the wind energy potential in these marine areas. The Black Sea is located between the Anatolian Peninsula and the southeastern part of Europe and it is connected to the Mediterranean Sea throughout the Marmara and Aegean seas, respectively. This basin can be divided into two main zones (west and east) with particular features, the coastlines of the sea being distributed between Bulgaria and Romania (west), Russia and Ukraine (north), and Georgia (east) and Turkey (south). Regarding the geographical characteristics of this sea, an average depth of $1315 \mathrm{~m}$, a total area of $436402 \mathrm{~km}^{2}$, and a water volume of $547000 \mathrm{~km}^{3}$ can be mentioned (Rotaru [1], Rusu et al. [2]). In the short term, the regional climate is under the influence of the NAO (North Atlantic Oscillations) mechanism, according to which during the winter time the storm events significantly increase under the influence of the cold air arriving from the northern regions. On a local scale, as in the case of the Novorossiysk region (Russia), the Bora events can restrict the maritime traffic since the wind conditions can easily exceed $15 \mathrm{~m} / \mathrm{s}$ (Alpers et al. [3]).
Regarding the Caspian Sea, it can be mentioned that this is in fact the largest enclosed water body in the world (40\% of the inland waters) being surrounded in about $7000 \mathrm{~km}$ by Russia and Kazakhstan (north), Turkmenistan (east), Iran (south), and Azerbaijan (west). It is located between Europe and Asia, and it has a surface of $371000 \mathrm{~km}^{2}$ and a volume of $78200 \mathrm{~km}^{3}$, while a particularity of this basin is that it is characterized by important oil fields (Rusu and Onea [4]). This basin has in the northern part a continental climate (hot summers and cold winters), while the southern part is defined by a subtropical regime (Stolberg et al. [5]). The weather conditions in this region are under the influence of the arctic air flow, including also the dry continental air masses from Kazakhstan and the air masses generated over the Atlantic Ocean (Mamaev [6]).

At this moment, the Black and Caspian Seas can be considered important sources of energy, but this regards mainly the fossil fuel reserves, while the possible benefits from the renewable energy resources are not yet well taken into consideration. From this perspective, the novelty of the present work consists in the fact that the wind energy potential in the vicinity of the coastlines of the two inland seas is discussed from a meteorological perspective. 


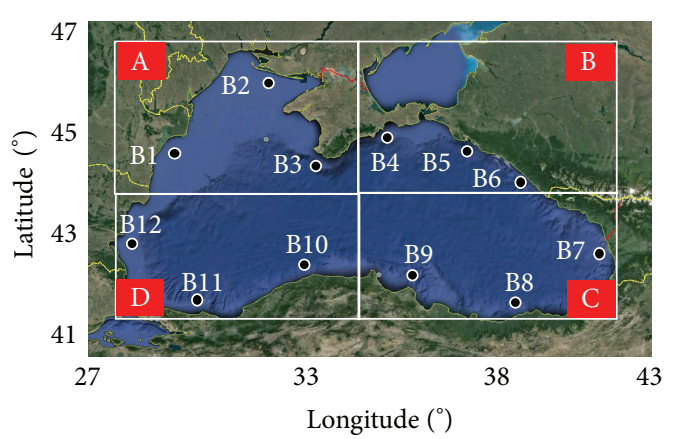

(a)

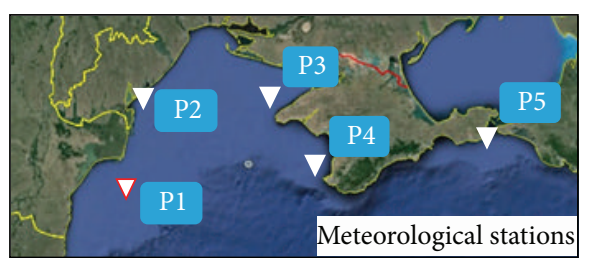

(b)

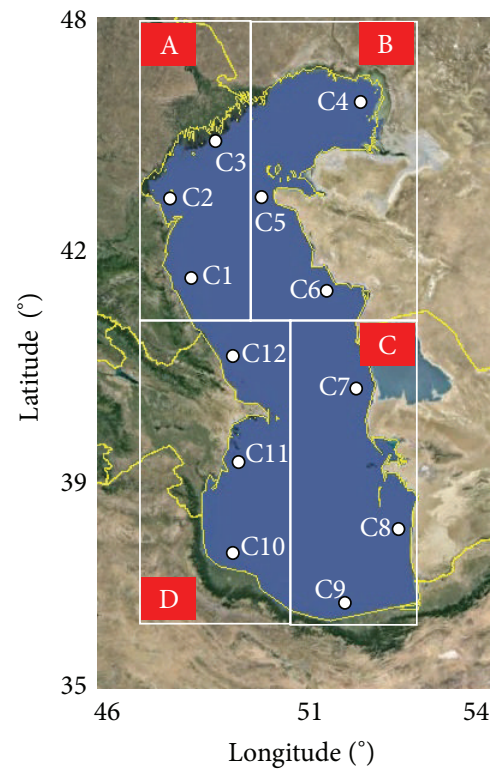

(c)

FIgURE 1: The geographical locations of the reference points considered in the coastal environments of (a) the Black Sea, (b) meteorological stations, and (c) the Caspian Sea. The in situ stations are located in the Black Sea area; most of them are in sector A. Figures are processed from Google Earth (2015).

\section{Methods and Materials}

2.1. The Target Areas. Figure 1 illustrates the basins of the Black and of the Caspian Seas, which are targeted in the present study. Each of the two basins was divided into four distinct rectangular areas denoted by $\mathrm{A}, \mathrm{B}, \mathrm{C}$, and $\mathrm{D}$, and twelve reference points were considered in each basin for a detailed evaluation. The $\mathrm{B}$ group and $\mathrm{C}$ group points are placed in the vicinity of the coastlines in water depths which do not exceed $30 \mathrm{~m}$, especially in the case of the Caspian
Sea, which is in the northern part characterized by large shallow water areas. For the Black Sea area, the reference points are located in the vicinity of Romania (B1), Ukraine (B2), Russia (B3-B6), Georgia (B7), Turkey (B8-B11), and Bulgaria (B12), respectively. In order to assess the accuracy and the limitations of the NCEP model, five meteorological stations located in the sector A were taken into account for comparisons, as follows: Gloria (denoted by P1), Primorskoe (P2), Chernomorskoe (P3), Khersonesskiy-Mayak (P4), and Zavetnoe (P5). The first point is placed in the Romanian sector, more precisely in the offshore area at a water depth of about $50 \mathrm{~m}$, while the rest of the points are located near the Ukrainian coast. All the in situ measurements are related to a $10 \mathrm{~m}$ height above the sea level and correspond to the time interval 1999-2008, except for the point P1, which covers only the time period 2003-2008. Some more details about these data can be found in Onea and Rusu [7].

Regarding the Caspian basin, the $\mathrm{C}$ points are divided between Russia (C1-C3), Kazakhstan (C4-C6), Turkmenistan (C7-C8), Iran (C9-C10), and Azerbaijan (C11 and $\mathrm{C} 12)$, respectively. For these target areas, it can be mentioned that Russia has coastlines in both seas, a fact which can be considered somehow an advantage, since the wind projects can be focused on one or another area according to the most favorable wind regime. The coastlines of Turkey can be also considered as representing another important area, since Turkey has the largest opening to the Black Sea $(1595 \mathrm{~km})$, compared, for example, with Romania $(245 \mathrm{~km})$.

2.2. The NCEP-CFSR Dataset. In general, a gap in the assessment of the conditions in the marine environment is represented by the limited amount of the in situ measurements. Nevertheless, during the recent years, this aspect was overreached by the development of the numerical models, which can produce extended reanalysis databases in both space and time. This type of data was also used in some previous studies to assess the global renewable energy resources in the marine areas (Rusu [8], Rusu and Onea [9]). A well-known reanalysis database is the one produced by the National Centers for Environmental Prediction (NCEP) from the United States, which provides information for a 31-year period (1979-2009). The full name of this project is NCEP-CFSR (Climate Forecast System Reanalysis) and it will be denoted in the present work by NCEP.

This is based on a system which uses a 5-day average and 6-hour forecast, being capable to simulate various parameters on a global scale, such as precipitation, temperature, pressure at the surface, or ice thickness. The wind conditions are reported at $10 \mathrm{~m}$ above the sea level (a.s.l.) in terms of the $U$ and $V$ components (in $\mathrm{m} / \mathrm{s}$ ) being computed based on 64 pressure layers, which are structured between the surface and $0.26 \mathrm{hPa}$ (24 levels) and from the surface to a $4700 \mathrm{~m}$ altitude (rest of the levels). More details regarding the bias correction, the assimilation processes, and the data quality can be found in the specification of the project (Kalnay et al. [10], Saha et al. [11]).

As a first step of the present work, the available NetCDF files were processed for the 10-year time interval 1999-2008, obtaining in this way daily values of the wind conditions with 


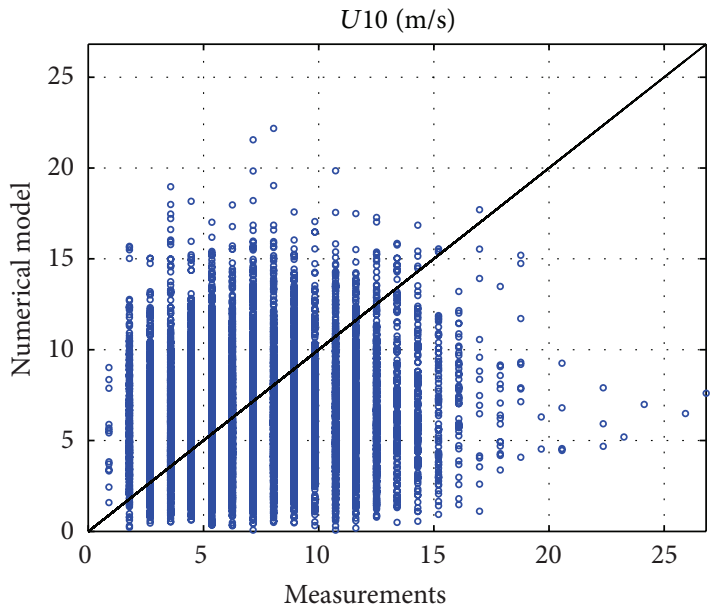

(a)

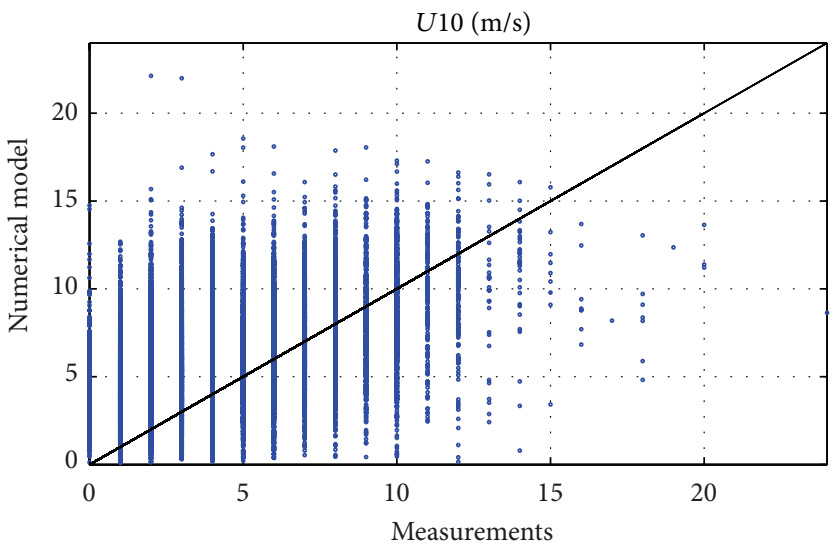

(c)

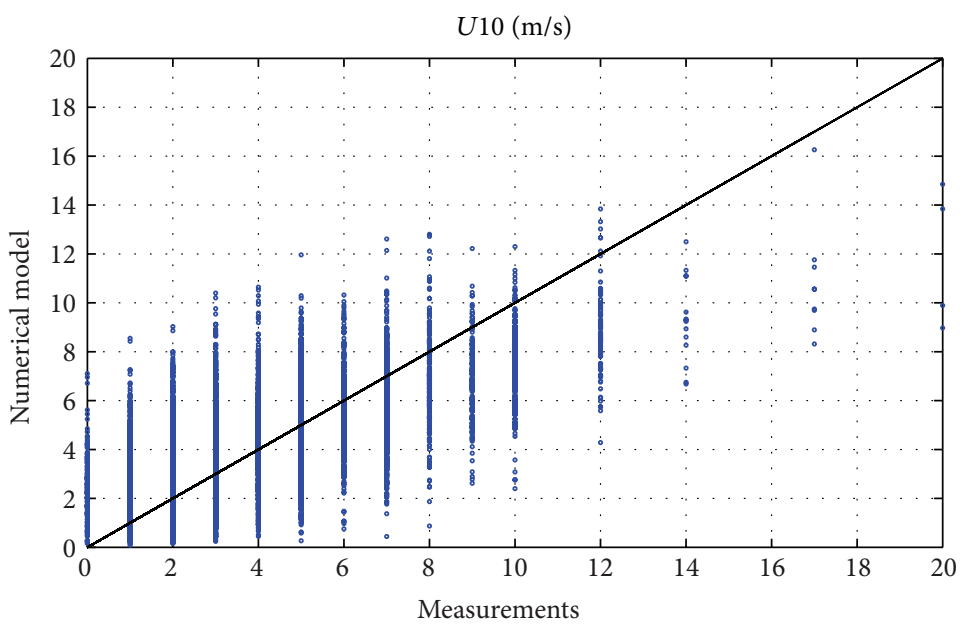

(b)

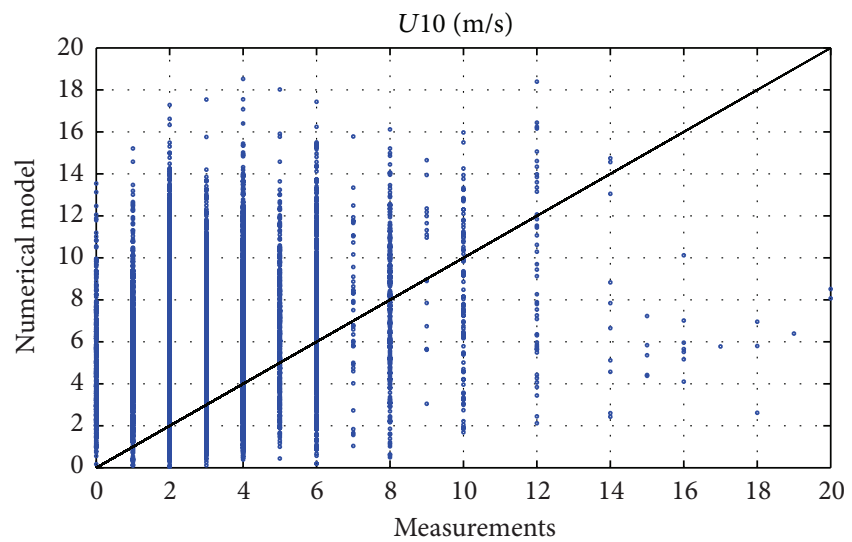

(d)

FIGURE 2: Scatter plots of the U10 parameter based on the in situ and NCEP model data considering the entire time interval 1999-2008 and the reference points: (a) P1, (b) P2, (c) P3, and (d) P5. The point P1 is reported only to the time period 2003-2008.

a step of 6 hours (00-06-12-18 UTC). In order to investigate different wind patterns, the initial data were particularly selected for the winter time period (October-March) and also for the diurnal (12-18 UTC) and nocturnal (00-06 UTC) intervals.

2.3. Methods. In Figure 2, a direct comparison between the in situ measurements and the NCEP data is presented corresponding to the reference points P1, P2, P3, and P5, considering the entire time interval 1999-2008. In this connection, a second processing of the NCEP data was performed in order to fit the hours corresponding to the in situ measurements. Thus, the NCEP model is characterized by a temporal resolution of 1 hour ( 24 data points per day) and for each particular point only the hours at which the measurements were reported were considered, as follows: P1 (01-07-13-19 UTC), P2 (09-21 UTC), P3 (03-09-1521 UTC), and P5 (09-21 UTC). The hours considered to be part of the diurnal interval are represented with bolds. The scatter diagram corresponding to the point P1 is presented in Figure 2(a), where it can be observed that the NCEP model tends to underestimate the wind speeds with higher
TABLE 1: $U 10$ statistics, in situ measurements at the meteorological stations (points P1-P5) against the NCEP data for the same geographical locations. The results are available for the time interval 1999-2008, being related to the total time.

\begin{tabular}{lcccccc}
\hline Point & $\begin{array}{c}X_{\text {med }} \\
(\mathrm{m} / \mathrm{s})\end{array}$ & $\begin{array}{c}Y_{\text {med }} \\
(\mathrm{m} / \mathrm{s})\end{array}$ & $\begin{array}{c}\text { Bias } \\
(\mathrm{m} / \mathrm{s})\end{array}$ & RMSE & SI & $R$ \\
\hline P1 & 7.21 & 6.42 & 0.78 & 4.49 & 0.62 & 0.12 \\
P2 & 4.08 & 4.43 & -0.35 & 2.07 & 0.5 & 0.63 \\
P3 & 4.46 & 6.03 & -1.57 & 3.37 & 0.75 & 0.44 \\
P4 & 4.61 & 6.00 & -1.39 & 3.57 & 0.77 & 0.36 \\
P5 & 3.28 & 6.27 & -2.98 & 4.46 & 1.35 & 0.22 \\
\hline
\end{tabular}

values. The best correlation can be observed for the point P2 (Figure 2(b)), while for the points P3 (Figure 2(c)) and P5 (Figure 2(d)) the numerical model seems to overestimate the local wind conditions.

The statistical parameters associated with the scatter diagrams are presented in Table $1 . X_{\text {med }}$ represents the mean value of the measurements and has a maximum value of 


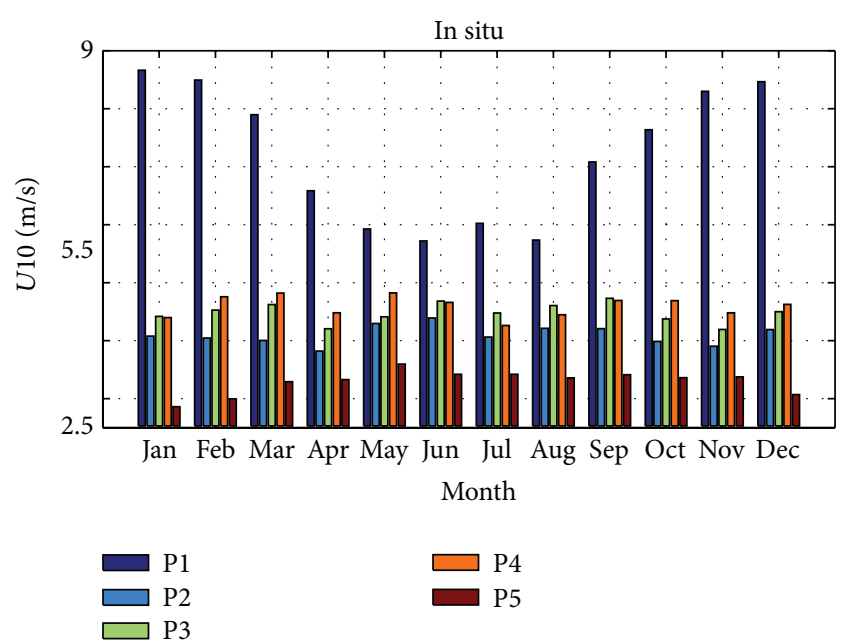

(a)

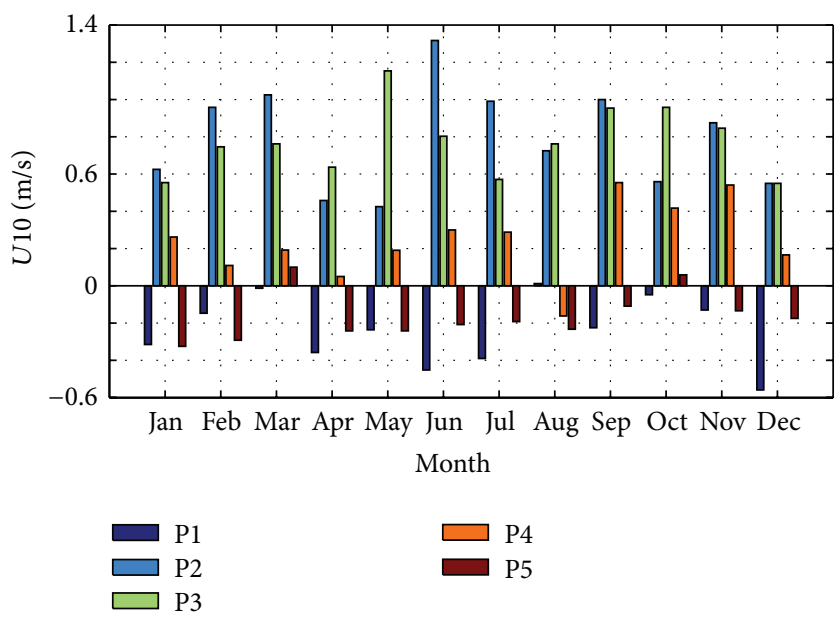

(c)

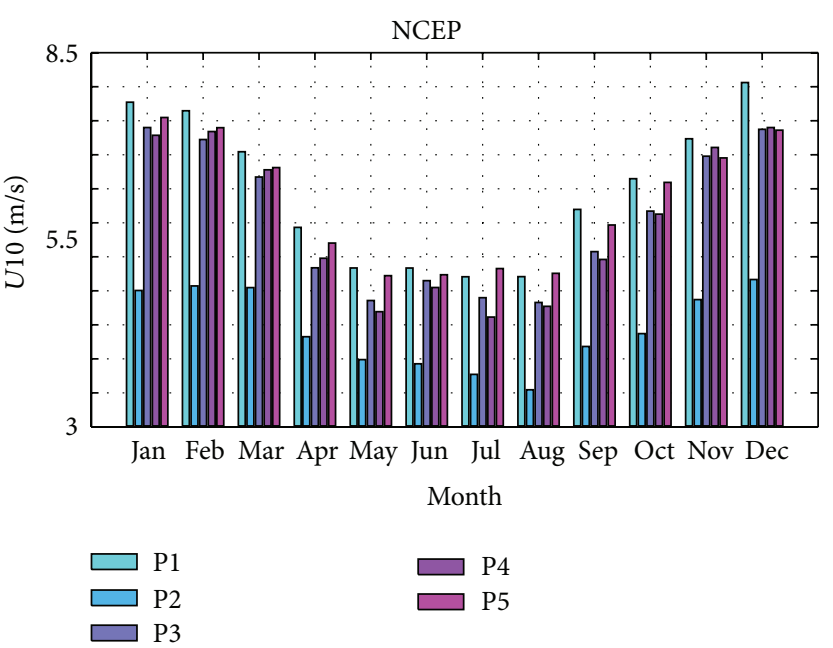

(b)

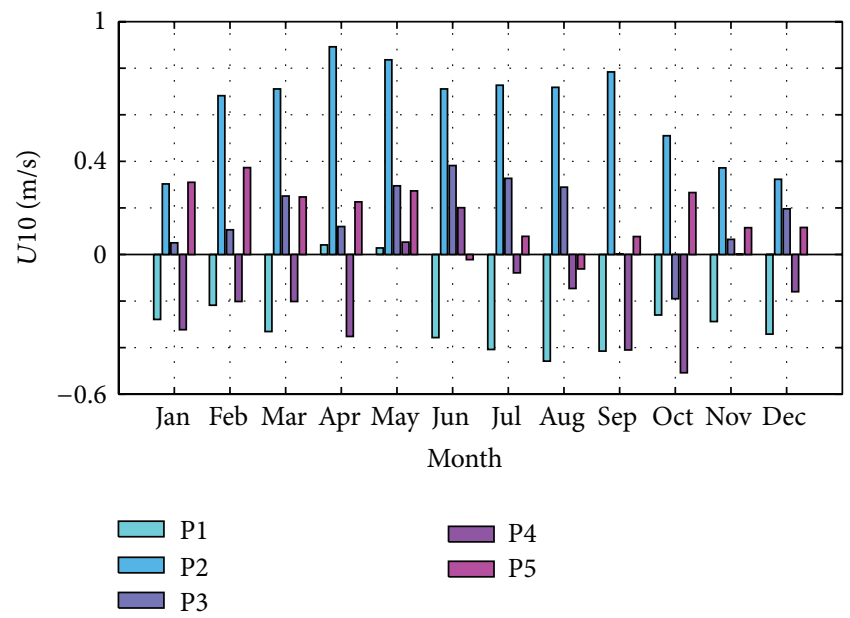

(d)

FIGURE 3: Evaluation of the wind conditions reported to the meteorological station sites for the time interval 1999-2008. The analyses are based on the in situ measurements and the NCEP data and correspond to the mean values of (a) monthly wind speeds registered at the meteorological stations, (b) monthly wind speeds provided by the NCEP model, (d) and (c) diurnal-nocturnal variations of the wind speeds according to the in situ measurements and the NCEP data, respectively.

$7.21 \mathrm{~m} / \mathrm{s}$ for the point P1 located in the offshore area, compared to the points P2-P5 (which are in the nearshore), where values in the range $3.28-4.61 \mathrm{~m} / \mathrm{s}$ are encountered. $Y_{\text {med }}$ is associated with the NCEP model and has significantly higher values, especially for the points P3-P5, while a good approximation is provided for the point $\mathrm{P} 2(4.43 \mathrm{~m} / \mathrm{s})$. The bias is negative for all the points, except for P1 where a value of $0.78 \mathrm{~m} / \mathrm{s}$ results. The Root Mean Square Error (RMSE) is frequently considered to assess the differences between the values provided by the numerical models and the ones coming from the measurements, where the zero value is considered as a reference (perfect score). According to this index, the best results are accounted by the point P2 (2.07), while the point $\mathrm{P} 5$ has a value of 4.46. Regarding the point P1, the higher values of the RMSE index (4.49) can be considered to be normal if we take into account that the errors tend to increase for higher wind speeds. The scatter index (SI), which links the RMSE to the $X_{\text {med }}$, presents values in the range 0.51.35, while for the Pearson correlation index $(R)$ also the point $\mathrm{P} 2$ presents the best results (0.63) compared to P1 (0.12) and P5 (0.22).

\section{Results}

3.1. Evaluation of the Wind Conditions. Figure 3 illustrates the distribution of the wind conditions corresponding to the parameter $U 10$ for the $\mathrm{P}$ group points. The monthly distribution of the in situ measurements (mean values) is indicated in Figure 3(a), from which it can be noticed that the point P1 (located offshore) stands out with higher wind speed values and also indicating clearly the differences between the summer and winter intervals. It has to be mentioned that in the present work the winter time is considered the 6month period between October and March. This point (P1) 


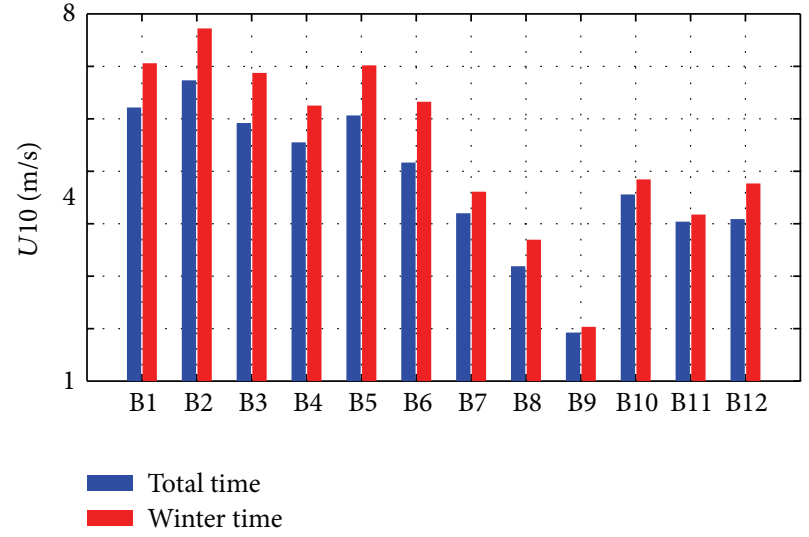

(a)

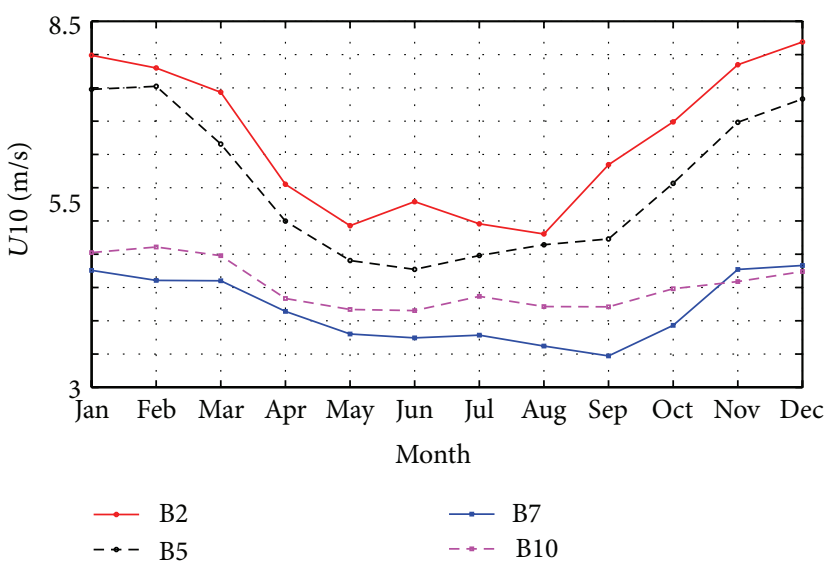

(c)

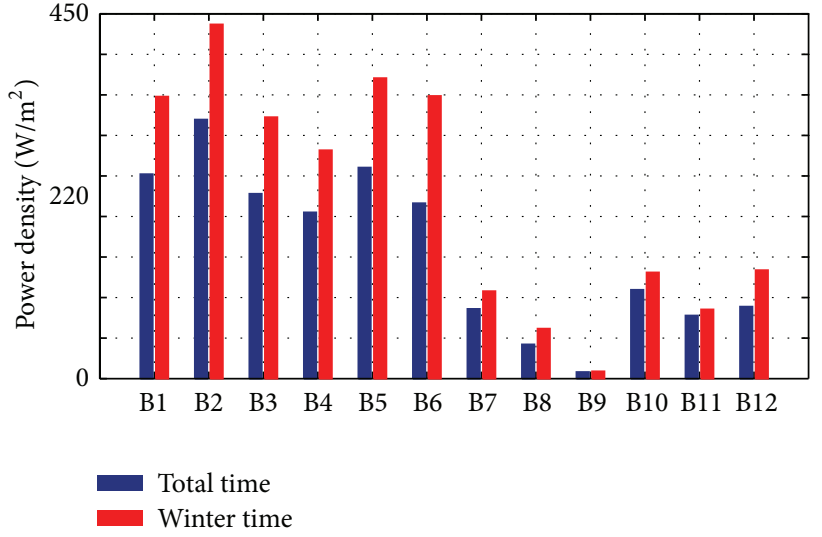

(b)

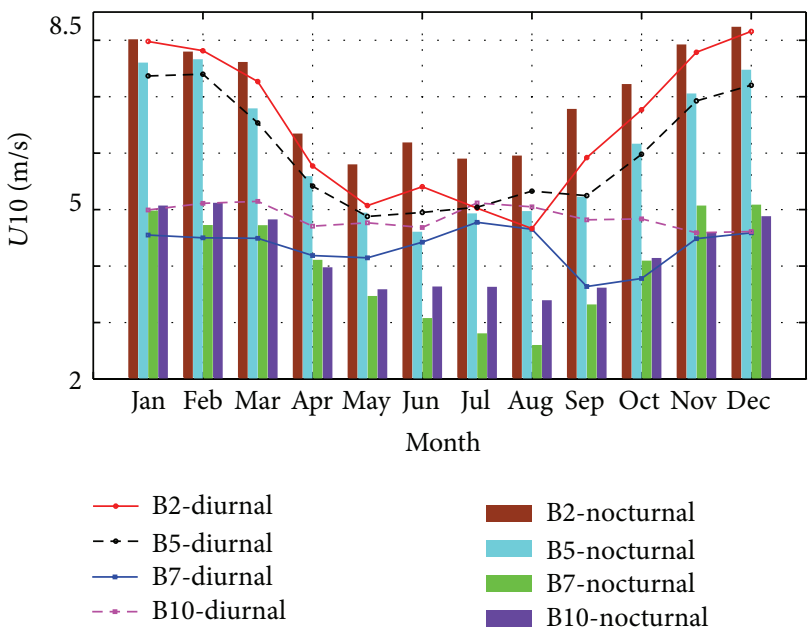

(d)

FIGURE 4: Assessment of the wind conditions in the Black Sea reported to a height of $10 \mathrm{~m}$. The results are based on the NCEP data (19992008) for the mean values of (a) wind speeds-total and winter time, (b) power density-total and winter time, (c) monthly wind speed (B2, B5, B7, and B10), and (d) monthly wind speed (B2, B5, B7, and B10)_diurnal and nocturnal.

presents during the winter values in the range $7.6-8.7 \mathrm{~m} / \mathrm{s}$, while a minimum of $5.7 \mathrm{~m} / \mathrm{s}$ is encountered during June and August, respectively. As regards the points P2-P5, it can be mentioned that during the winter time more important values are observed in March with $4 \mathrm{~m} / \mathrm{s}$ in P2, $4.6 \mathrm{~m} / \mathrm{s}$ in $\mathrm{P} 3,4.8 \mathrm{~m} / \mathrm{s}$ in $\mathrm{P} 4$, and $3.3 \mathrm{~m} / \mathrm{s}$ in $\mathrm{P} 5$. Compared to this time interval, which is typically considered to be more energetic, some summer months may report similar values, as in the case of May: $4.3 \mathrm{~m} / \mathrm{s}$ in P2, $4.4 \mathrm{~m} / \mathrm{s}$ in P3, $4.8 \mathrm{~m} / \mathrm{s}$ in P4, and $3.6 \mathrm{~m} / \mathrm{s}$ in P5. On the opposite side, the NCEP model presents a smooth distribution of the monthly values (Figure 3(b)), clearly highlighting the winter season and indicating the point $\mathrm{P} 2$ as being the less energetic one. In this case, the point P1 is considered to be more energetic with values located in the range $6.6-8.1 \mathrm{~m} / \mathrm{s}$ (winter) and 5.2-6.2 $\mathrm{m} / \mathrm{s}$ (summer), closely followed by the group points P3-P5 with $6.1-7.5 \mathrm{~m} / \mathrm{s}$ (winter) and 4.6-5.9 m/s (summer), respectively.

The differences between the diurnal and nocturnal intervals, as reflected by the in situ measurements, can be observed in Figure 3(c). The point P1 presents in general considerably higher values of the wind speed corresponding to the nocturnal conditions, indicating a maximum difference of $0.55 \mathrm{~m} / \mathrm{s}$ in December. At the same time, the point P5 presents higher nocturnal values, the differences being located in the range $0-0.3 \mathrm{~m} / \mathrm{s}$. More significant diurnal wind conditions can be encountered near the points $\mathrm{P} 2-\mathrm{P} 4$, higher variations being reported by $\mathrm{P} 2$, especially in June $(1.32 \mathrm{~m} / \mathrm{s})$ or by $\mathrm{P} 3$, with a difference of $1.15 \mathrm{~m} / \mathrm{s}$ in May. Regarding the NCEP model (Figure 3(d)), it can be observed that this indicates more important diurnal conditions for the points P1 and P4, respectively. According to this dataset, the point P3 presents more important diurnal conditions during October, when a difference of $0.2 \mathrm{~m} / \mathrm{s}$ is encountered.

Figure 4 illustrates the distribution of the parameters $U 10$ in the Black Sea area, structured in total and winter time intervals, respectively. According to the NCEP data, it can be noticed that the wind speed tends to decrease from the point B2 to B9 which are aligned along the northern, northeastern, and southern coasts of the sea, respectively. The winter season presents higher wind speeds and, according to Figure 4(a), 


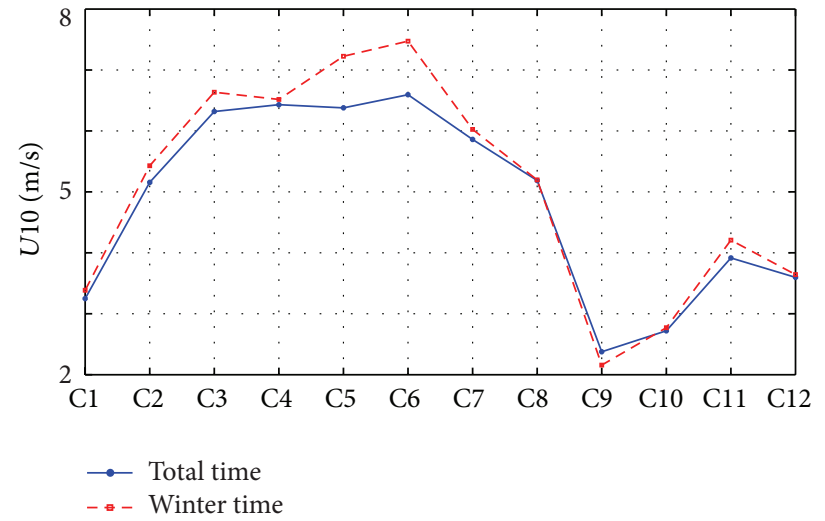

(a)

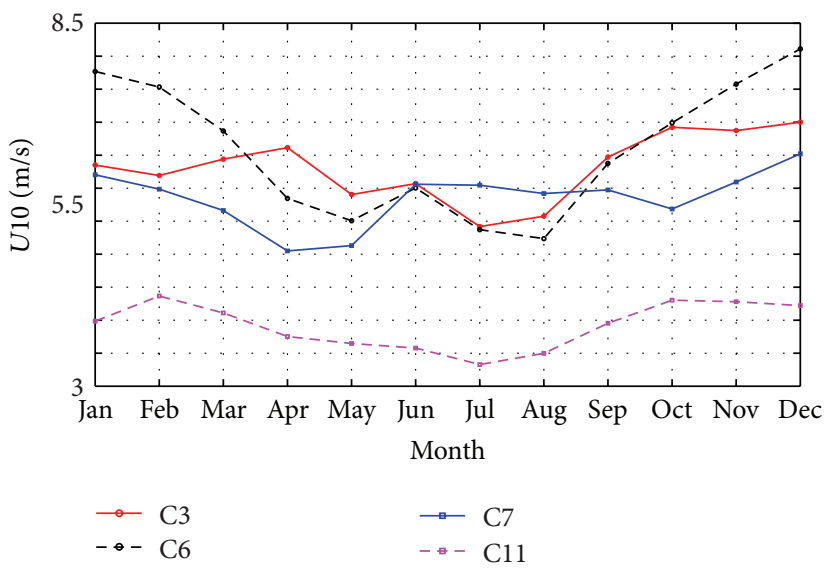

(c)

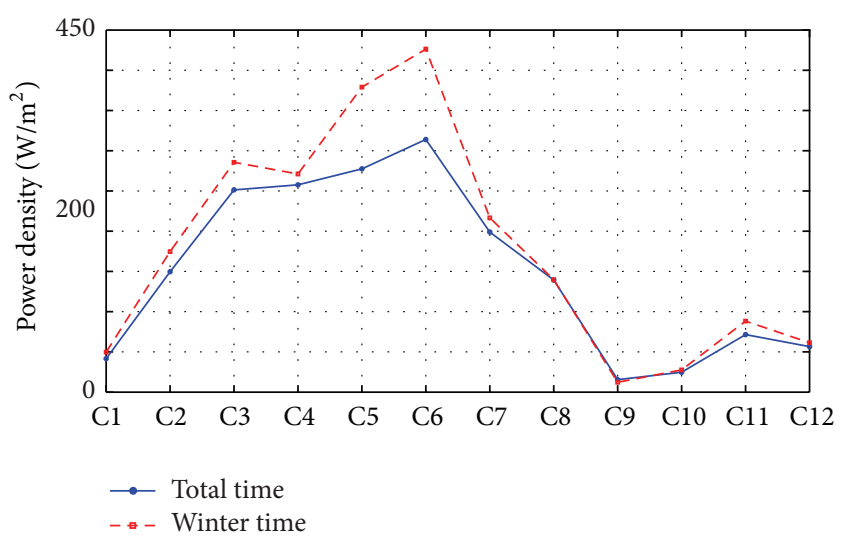

(b)

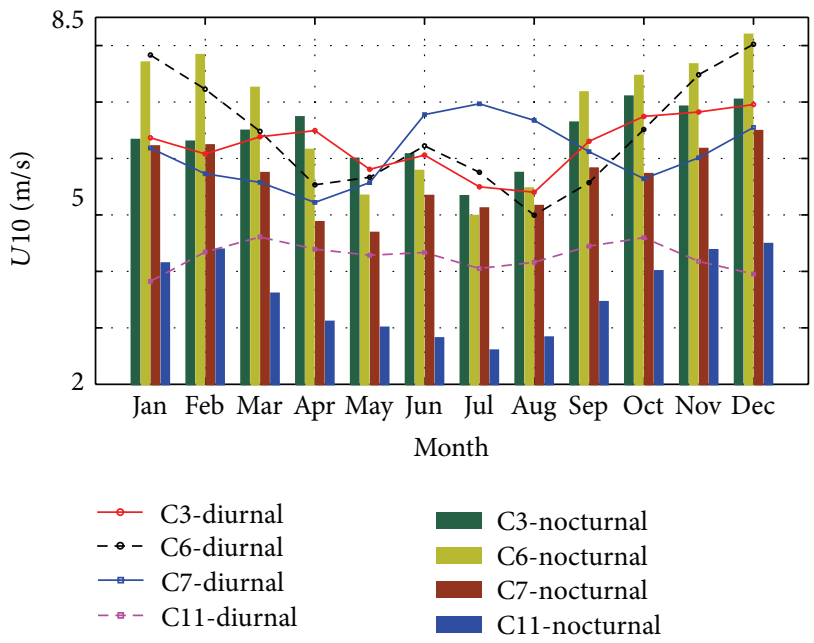

(d)

FIGURE 5: Assessment of the wind conditions in the Caspian Sea reported to a height of $10 \mathrm{~m}$. The results are based on the NCEP data (19992008) for the mean values of (a) wind speeds-total and winter time, (b) power density-total and winter time, (c) monthly wind speed (C3, C6, C7, and C11), and (d) monthly wind speed (C3, C6 C7, and C11)-diurnal and nocturnal.

the following points stand out from each reference sector: B2-7.7 m/s (sector A), B5-7 m/s (sector B), B7-4.58 m/s (sector $\mathrm{C}$ ), and $\mathrm{B} 10-4.81 \mathrm{~m} / \mathrm{s}$ (sector D).

Besides the wind speed, another parameter that is used frequently to express the wind energy potential is the power density (in $\mathrm{W} / \mathrm{m}^{2}$ ), which can be defined as (Fiedler and Adams [12]):

$$
P=\frac{1}{2} \rho U 10^{3},
$$

where $\rho$ refers to the air density $\left(1.22 \mathrm{~kg} / \mathrm{m}^{3}\right)$ and $U 10$ represents the wind speed reported to a $10 \mathrm{~m}$ height above the sea level. Regarding the power density parameter, presented in Figure 4(b), more important energetic peaks are noticed in B2 $\left(437 \mathrm{~W} / \mathrm{m}^{2}\right)$, which is followed by the points B5 and B6 with values in the range $349-371 \mathrm{~W} / \mathrm{m}^{2}$. For the group points B7-B12, the values do not exceed $134 \mathrm{~W} / \mathrm{m}^{2}$.

The monthly distribution of the parameter $U 10$ (mean values) for the points $\mathrm{B} 2, \mathrm{~B} 5, \mathrm{~B} 7$, and $\mathrm{B} 10$ is presented in Figure 4(c). From this figure, it can be observed that the values reflect the total/winter distributions, where the point $\mathrm{B} 2$ is more energetic and the point $\mathrm{B} 7$ is the least energetic one. More significant values are noticed during the winter time, in particular during January and February, when values of B2-8 m/s, B5-7.5 m/s, B7-4.7 m/s, and B10$5.1 \mathrm{~m} / \mathrm{s}$ are encountered in these points. Figure $4(\mathrm{~d})$ illustrates the diurnal/nocturnal distributions of the wind conditions from which it can be mentioned that the point B5 presents the smallest variations. Regarding the point B2, this presents higher nocturnal values during the interval May-October, when a maximum difference of $0.8 \mathrm{~m} / \mathrm{s}$ is noticed in September. As regards the point B7, during the summer time (MayAugust), the diurnal values are considerably higher, while a reverse trend is observed in the winter, when the diurnal wind speed has a maximum value of $5 \mathrm{~m} / \mathrm{s}$, the differences being about $0.36 \mathrm{~m} / \mathrm{s}$. Regarding the point $\mathrm{B} 10$, it can be noticed that the diurnal conditions are more consistent throughout the entire year, especially for the interval April-October.

For the Caspian Sea area, a similar analysis is presented in Figure 5, considering the same time interval (1999-2008). Regarding the distribution of the wind speed (Figure 5(a)) it 
TABLE 2: Statistical analysis of the NCEP data, corresponding to the total time (TT) and winter time (WT), respectively. The results cover the ten-year time interval 1999-2008.

\begin{tabular}{|c|c|c|c|c|c|c|c|c|c|}
\hline \multirow{3}{*}{ Results } & \multirow{3}{*}{ Time interval } & \multicolumn{8}{|c|}{ Point } \\
\hline & & \multicolumn{4}{|c|}{ Black Sea } & \multicolumn{4}{|c|}{ Caspian Sea } \\
\hline & & B2 & B5 & B7 & $\mathrm{B} 10$ & C3 & C6 & C7 & $\mathrm{C} 11$ \\
\hline \multirow{2}{*}{$U 10(\mathrm{~m} / \mathrm{s})$} & TT & 6.71 & 6.04 & 4.17 & 4.52 & 6.31 & 6.59 & 5.86 & 3.91 \\
\hline & WT & 7.70 & 7.00 & 4.58 & 4.81 & 6.63 & 7.47 & 6.02 & 4.20 \\
\hline \multirow{2}{*}{$95 \%(\mathrm{~m} / \mathrm{s})$} & TT & 12.37 & 11.86 & 8.06 & 8.93 & 11.22 & 12.57 & 10.42 & 7.61 \\
\hline & WT & 13.28 & 13.16 & 8.62 & 9.53 & 11.62 & 13.64 & 10.73 & 8.28 \\
\hline \multirow{2}{*}{ Extreme (m/s) } & TT & 24.81 & 21.92 & 16.33 & 19.39 & 18.8 & 18.83 & 18.49 & 16.83 \\
\hline & WT & 24.81 & 21.92 & 16.33 & 19.39 & 17.41 & 18.83 & 18.49 & 16.83 \\
\hline \multirow{2}{*}{ Power density $\left(\mathrm{W} / \mathrm{m}^{2}\right)$} & TT & 319.6 & 260.4 & 86.05 & 109.6 & 251.3 & 314 & 198.9 & 71.5 \\
\hline & WT & 436.9 & 370.7 & 107.9 & 131 & 285.6 & 426.3 & 216.6 & 88.3 \\
\hline
\end{tabular}

can be noticed that higher values were reported by the group points $\mathrm{C} 2-\mathrm{C} 8$, where the point $\mathrm{C} 6$ presents a maximum of $6.59 \mathrm{~m} / \mathrm{s}$ (total time) and $7.47 \mathrm{~m} / \mathrm{s}$ (in winter). On the opposite side, the point C9 has values which do not exceed $2.4 \mathrm{~m} / \mathrm{s}$, with the mention that the values encountered during the total time are more significant. In relationship to each reference sector, it can be mentioned that the most important values are noticed in C3-6.63 m/s (sector A), C6-7.47 m/s (sector B), C7-6.1 m/s (sector C), and C11-4.2 m/s (sector D).

The evolution of the power density is presented in Figure 5(b), where the points C5 and C6 present higher values, especially during the winter time, while the point $\mathrm{Cl}$ and the group of points $\mathrm{C} 9-\mathrm{C} 12$ do not exceed the limit of $49 \mathrm{~W} / \mathrm{m}^{2}$. Similar to the wind speed, from the sector considered, the following points present maximum values: $\mathrm{C} 3-286 \mathrm{~W} / \mathrm{m}^{2}, \mathrm{C} 6-426 \mathrm{~W} / \mathrm{m}^{2}, \mathrm{C} 7-217 \mathrm{~W} / \mathrm{m}^{2}$, and $\mathrm{Cll}-$ $88 \mathrm{~W} / \mathrm{m}^{2}$. Since some reference points already stand out in terms of their energy, a more detailed evaluation of the monthly distribution is presented in Figure 5(c). As expected, the point C11 presents lower wind speed values $(<4.4 \mathrm{~m} / \mathrm{s})$ while the point $\mathrm{C} 6$ seems to be more energetic during the time interval November-March, when the mean wind speed values can reach a maximum of $7.6 \mathrm{~m} / \mathrm{s}$. The point $\mathrm{C} 7$ presents lower wind speed values during the interval April-May, when a minimum of $5 \mathrm{~m} / \mathrm{s}$ was registered.

The diurnal/nocturnal distributions of the wind conditions are given in Figure 5(d), where various patterns can be noticed. Thus, for the point $\mathrm{C} 3$, a higher difference is noticed during the summer time, when the nocturnal conditions are also significantly higher with differences of $0.33 \mathrm{~m} / \mathrm{s}$ in September and October. For the point C6, the nocturnal values can have differences of $0.6 \mathrm{~m} / \mathrm{s}$ (February), $0.77 \mathrm{~m} / \mathrm{s}$ (March), and almost $1 \mathrm{~m} / \mathrm{s}$ (August and September). The diurnal wind conditions are higher in the point $\mathrm{C}$, especially in the interval April-September, when a difference of $1.8 \mathrm{~m} / \mathrm{s}$ is noticed in July, while a similar pattern is characteristic to the point C11, which for the interval March-October presents a maximum difference of $1.5 \mathrm{~m} / \mathrm{s}$ (in June) and a minimum of $0.6 \mathrm{~m} / \mathrm{s}$ (in October).

Table 2 presents a statistical analysis of the main wind parameters from the Black and the Caspian Seas, where besides the average values of the wind parameters $U 10$ and the power density, there were also included the 95 percentile (denoted by 95\%) and the extreme values. The 95 percentile presents for the Caspian Sea values in the range 7.61-12.57 m/s (total time) and $8.28-13.64 \mathrm{~m} / \mathrm{s}$ (winter season), while in the Black Sea these values are in the interval $8.06-12.37 \mathrm{~m} / \mathrm{s}$ (total time) and $8.62-13.28 \mathrm{~m} / \mathrm{s}$ (in winter).

Another important parameter in the process of evaluating a particular location is the direction from which the wind is blowing. Figure 6 illustrates the wind roses, which are represented corresponding to the meteorological points P1P4 based on the time period 1999-2008, the results being structured in the diurnal and nocturnal intervals. At a first analysis, it can be observed that the NCEP data have smoother wave roses. Moreover, they are grouped around a particular direction, compared to the in situ measurements, which present a more irregular distribution. For the point $\mathrm{Pl}$, the in situ data indicate the northern sector as being dominant, with the mention that during the diurnal time it is possible to encounter wind conditions from the northeastern direction. The NCEP model suggests that during the diurnal period the southern sector is the dominant one, while during the nighttime the northeastern-southwestern line appears to be the most relevant. As regards the point $\mathrm{P} 2$, it can be mentioned that there is a small agreement between the two datasets, in the sense that both indicate that the southern sector is dominant during the nocturnal interval, with the mention that the in situ values are located more in the southeastern sector. Maybe the best agreement is reported by the point $\mathrm{P} 4$, which indicates that the southeastern sector is one of the most important (diurnal and nocturnal), while the in situ values also indicate the northern sector.

Based on the NCEP dataset, Figure 7 illustrates a similar analysis, but this time only for the total time data (19992008) and by considering only some reference points from the two target areas. In general, it can be noticed that the wind direction from the two seas does not follow a regular pattern, each region being defined by some particular features. Regarding the Black Sea (Figure 7(a)), it can be mentioned that the points from the northern part of the basin present a grouped distribution of the wind directions, with no clear peaks, except for the point B5, which indicates the northeastern sector, an aspect that could be associated 


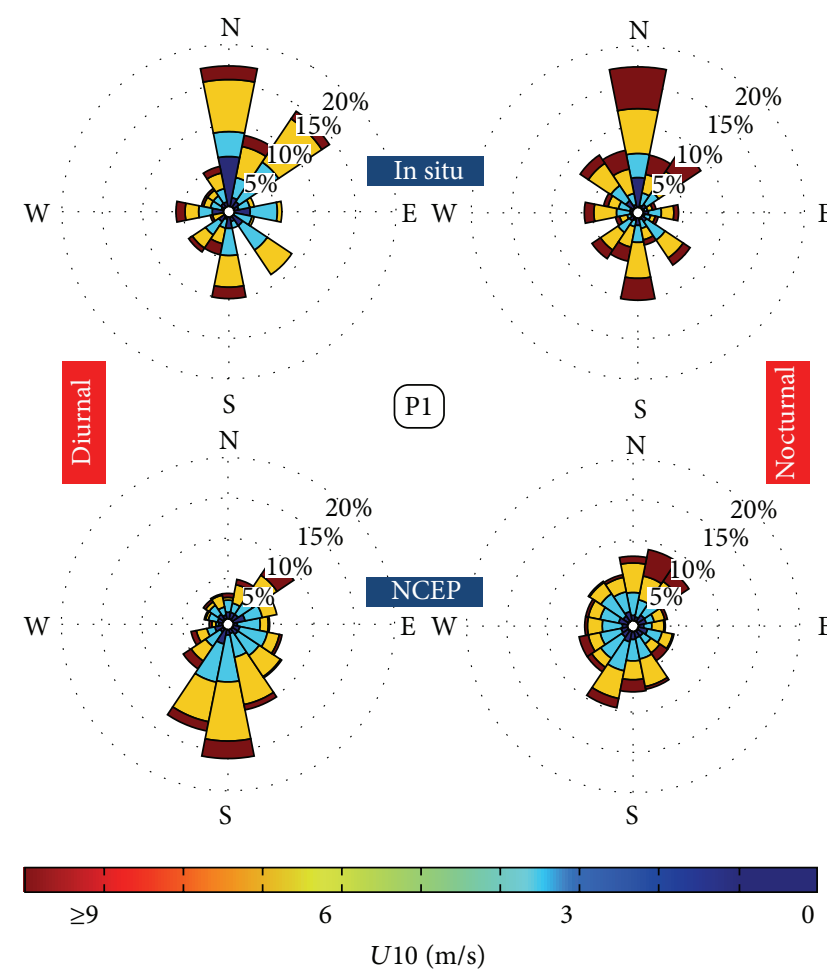

(a)

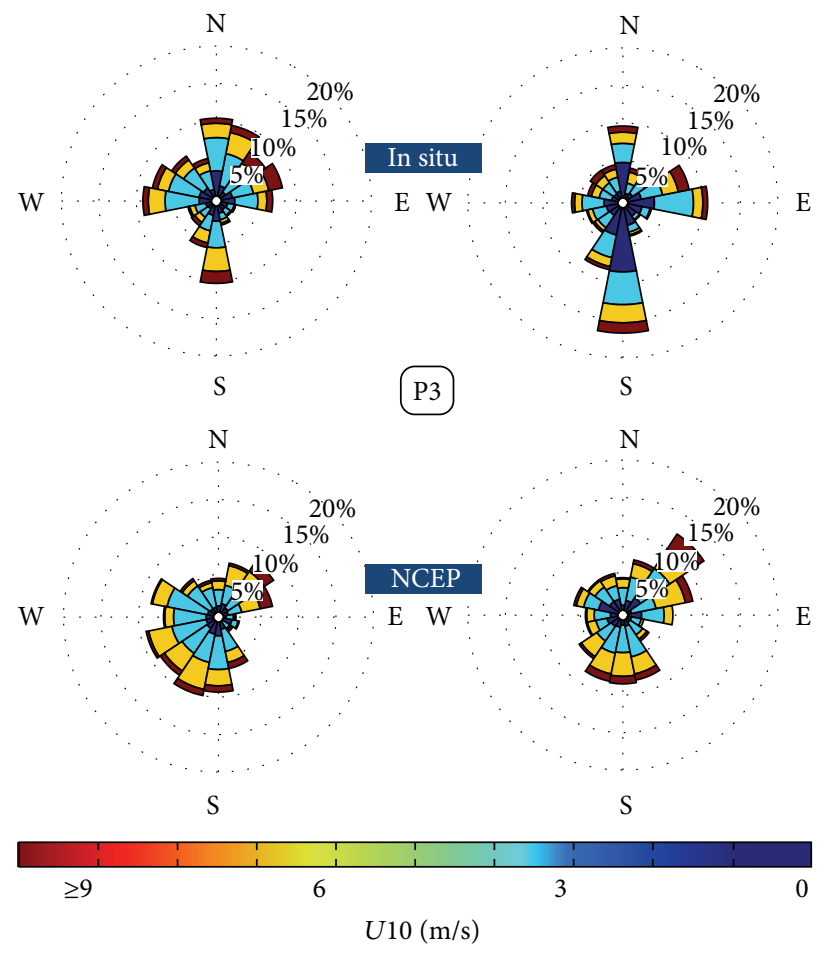

(c)

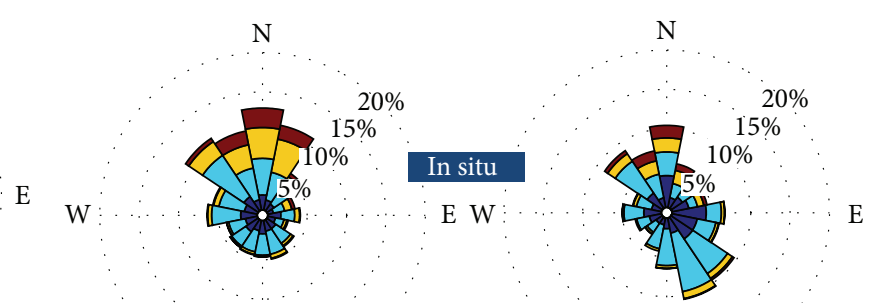

P2

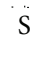

$\mathrm{N} \quad \mathrm{N}$

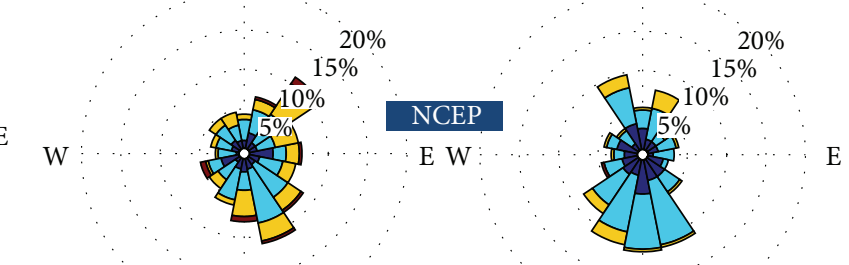

S

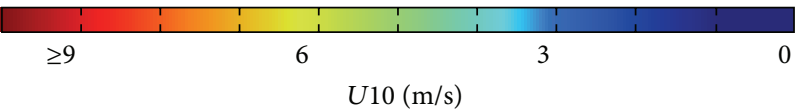

(b)
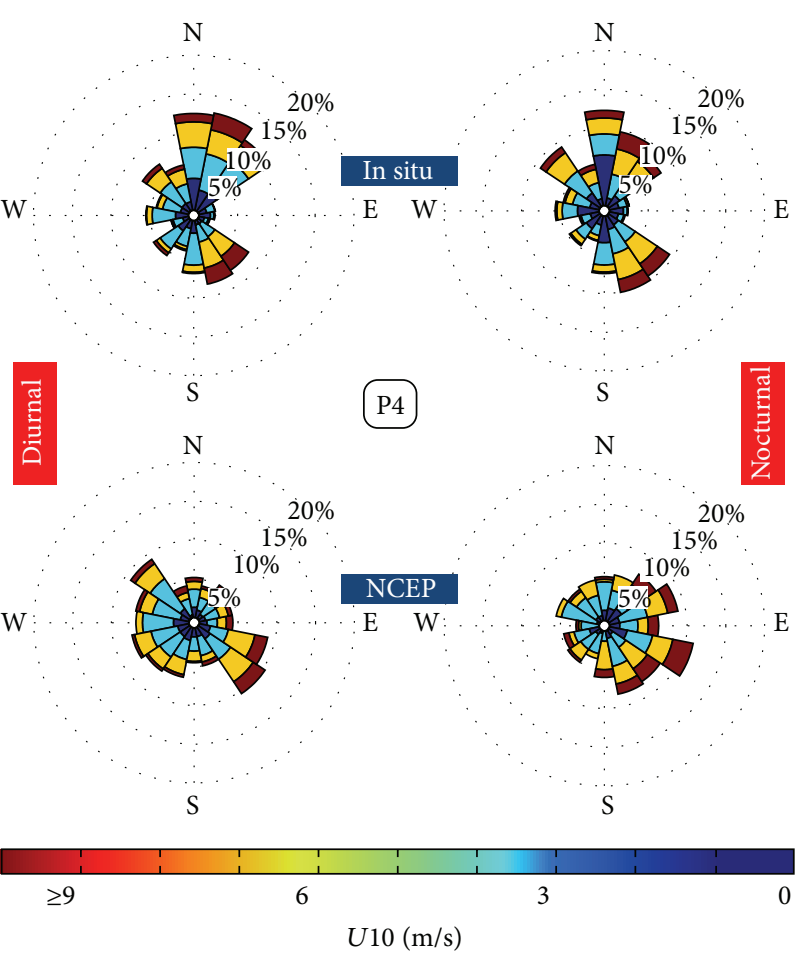

(d)

Figure 6: Wind roses reported to the meteorological stations, during the time period 1999-2008. The results are structured in the diurnal and nocturnal intervals, corresponding to the points (a) P1, (b) P2, (c) P3, and (d) P4. 

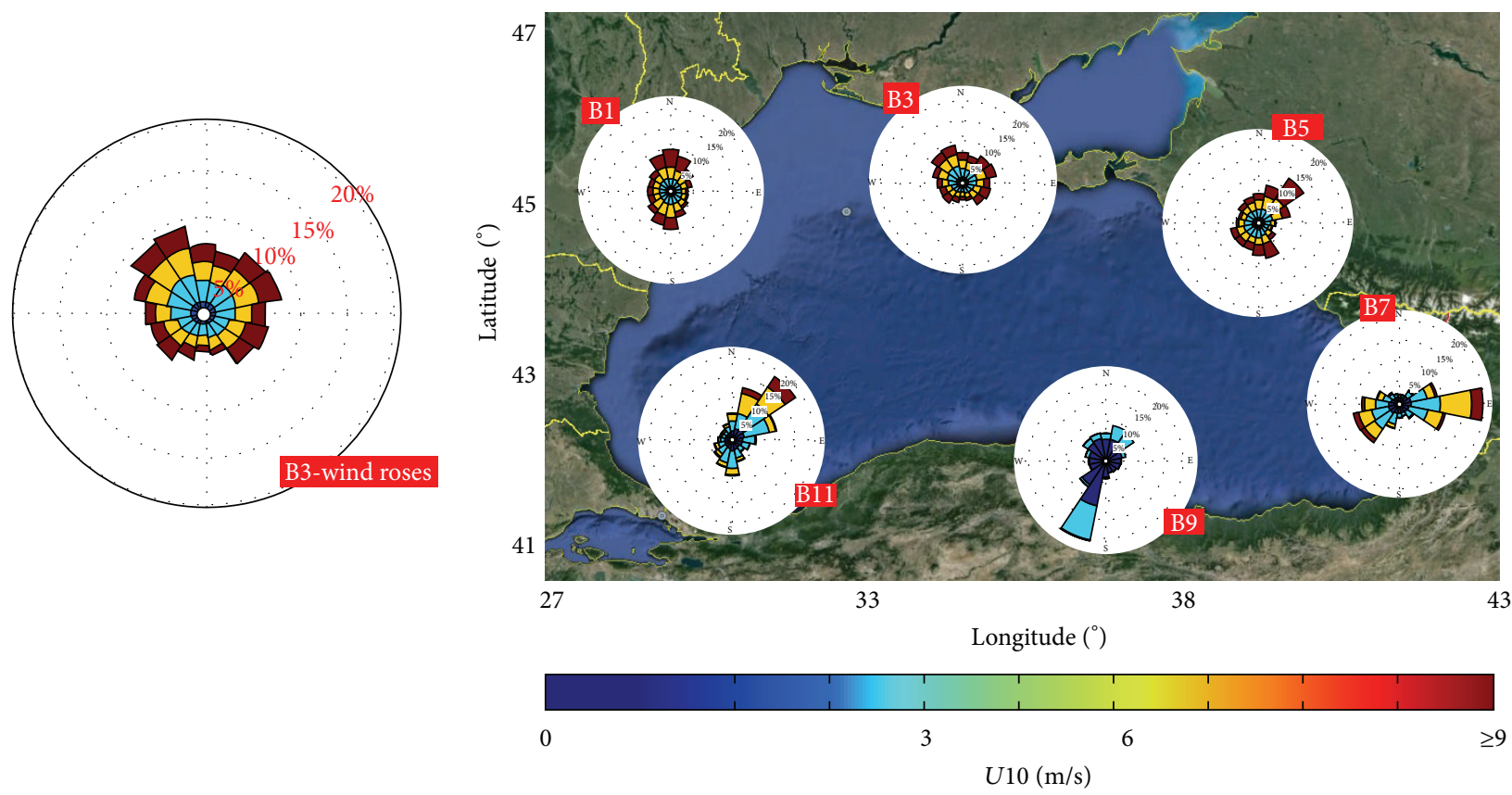

(a)

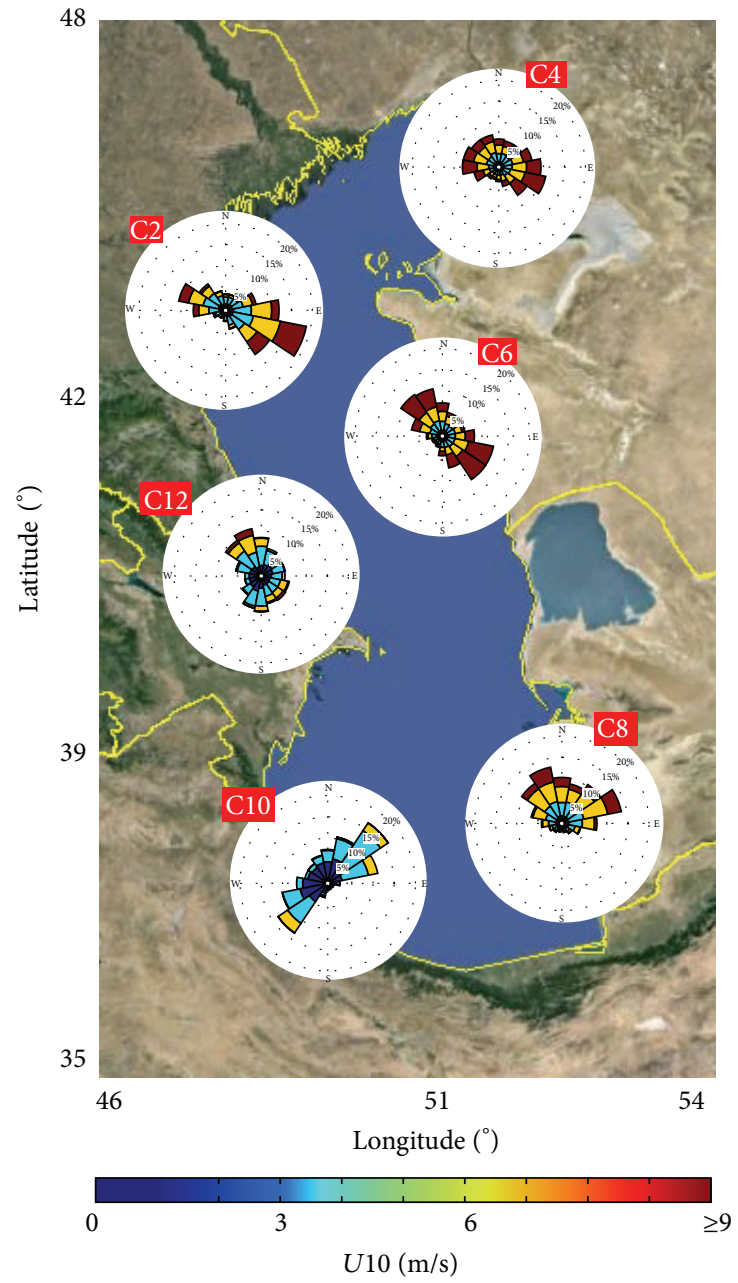

(b)

FIGURE 7: Wind roses corresponding to some relevant points from (a) the Black Sea and (b) the Caspian Sea. The NCEP data correspond to the 10-year time interval (1999-2008). 

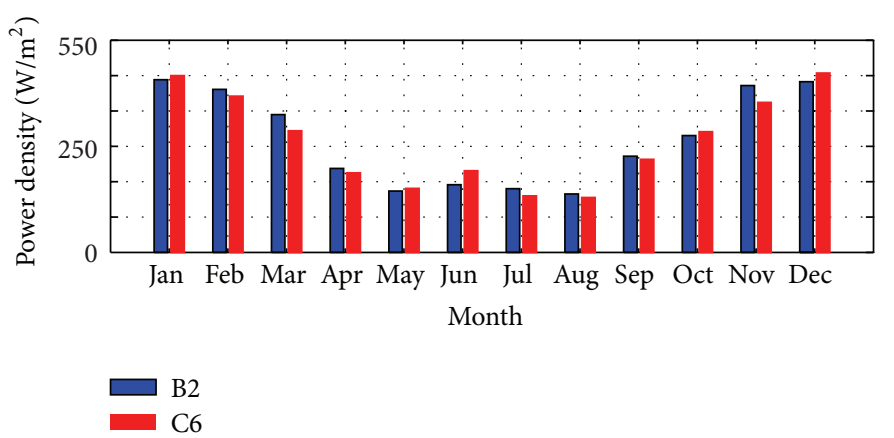

(a)
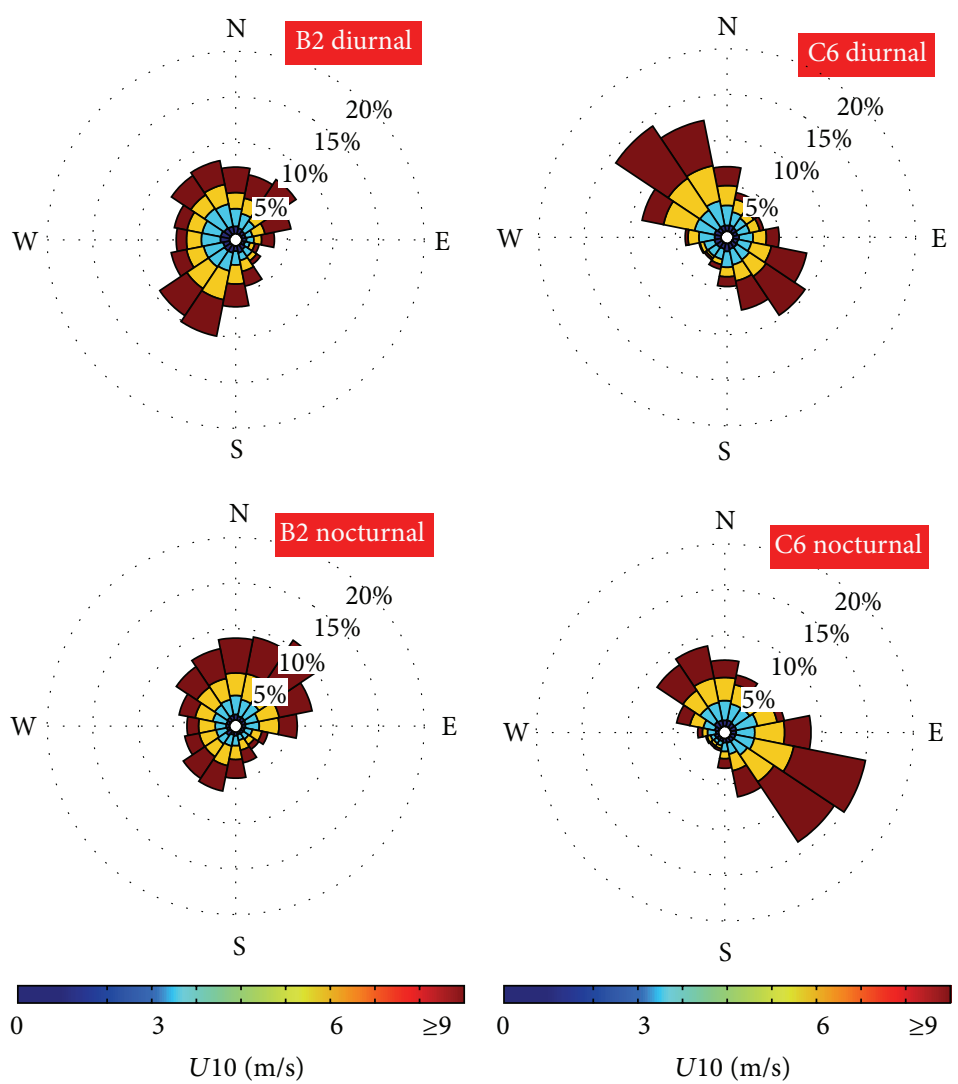

(b)

(c)

FIguRE 8: Comparison of the wind conditions corresponding to the points B2 (the Black Sea) and C6 (the Caspian Sea), where (a) monthly mean power density, (b) diurnal and nocturnal wind roses for the reference point B2, and (c) diurnal and nocturnal wind roses for the reference point C6 are reported.

with the influence of the Bora events from the Novorossiysk region. More obvious peaks are observed in the points B7 (from the east), B9 (from the southwest), and B11 (from the northeast), which instead present lower wind speeds than the points located close to the northern coast. In the Caspian Sea (Figure 7(b)), it can be noticed that the points from the northern part $(\mathrm{C} 2, \mathrm{C} 4$, and $\mathrm{C} 6)$ present a significant percentage of the wind conditions higher than $7 \mathrm{~m} / \mathrm{s}$. In terms of the wind direction the point $\mathrm{C} 2$ indicates the northeastern sector as dominant, while C6 is under the influence of the northwestern and northeastern winds. For the point C8, the general occurrence of the wind can be associated with the onshore area while in about $16 \%$ of the cases the wind conditions can occur from the northern sector (along the coastline).

A closer look at the wind conditions of the two target areas is presented in Figure 8, considering only the most representative locations. As it was previously noticed, based on the NCEP data, it is shown that the point B2 seems to present the best wind resources from the entire sea, while the point C6, located in the vicinity of Kazakhstan, was considered since it presents a significant wind potential, as it can be noticed from Figure 5(a) (mean values).

Figure 8(a) illustrates the monthly evolution of the power density. First of all, the differences between the winter time and the rest can be noticed and also that the 
point B2 does not present higher values than the point C6. Regarding the point B2, it can be observed that a maximum of $488 \mathrm{~W} / \mathrm{m}^{2}$ is reported in January, while compared to C6 the following differences can be noticed: January- $11 \mathrm{~W} / \mathrm{m}^{2}$, March $-45 \mathrm{~W} / \mathrm{m}^{2}$, May- $7.5 \mathrm{~W} / \mathrm{m}^{2}$, July$20 \mathrm{~W} / \mathrm{m}^{2}$, September $-8 \mathrm{~W} / \mathrm{m}^{2}$, and November $-47 \mathrm{~W} / \mathrm{m}^{2}$, respectively.

The most severe variation can be associated with the diurnal/nocturnal distribution of the wind direction, which is illustrated for the point B2 in Figure 8(b). During the diurnal interval, a significant percentage of the wind is coming from the southwestern sector (sea region) compared to the night interval, when the northern sector (onshore region) is dominant, while regarding the wind speeds there are no visible variations. For the point C6 (Figure 8(c)), the northwestern sector seems to be more representative, while a reverse trend is observed for the nocturnal period when the wind conditions from the southeastern sector occur more frequent.

\section{Discussions of the Results}

Although at this moment in Europe, the ocean boundaries present more interest, since the wind conditions seem to be in general more energetic there, possible benefits can be obtained also from the inland basins such as the Mediterranean and Black seas (Ahmed Shata and Hanitsch [13], Onea and Rusu [14]) or from the Caspian Sea (Kerimov et al. [15], Rahmanov et al. [16]), which is relatively close to this geographic region.

Since the NCEP dataset can be considered a blended source of data, from the comparisons with the in situ measurements (wind speed and direction), it was noticed that this type of data tends to average the wind conditions both in the offshore or the nearshore locations. In order to provide a better perspective on the results obtained for the two basins, in this section, also some satellite measurements will be analyzed, which were processed corresponding to the locations of the same reference points, respectively: B1-B12 (Black Sea) and $\mathrm{C} 1-\mathrm{Cl} 2$ (Caspian Sea). These measurements are coming from the AVISO (Archiving, Validation and Interpretation of Satellite Oceanographic Data) program [17], which is a multimission project where multiple satellite missions are combined and calibrated in order to obtain an accurate dataset available on a global scale. In the present work, the wind measurements were processed for the time interval 2010-2014 (5 years), each time series being characterized by one value per day.

Figure 9 illustrates the evolution of the parameter $U 10$ for the reference points in the Black Sea. The seasonal distribution is presented in Figure 9(a) for the total and the winter time periods, where it can be observed that the points located in the western part of the sea present more energetic features. According to these measurements, the point B2 presents more important values with $4.1 \mathrm{~m} / \mathrm{s}$ during total time and $5.1 \mathrm{~m} / \mathrm{s}$ in winter, closely followed by B1 with $5 \mathrm{~m} / \mathrm{s}$ (winter), B3-4.9 m/s (winter), B4-4.8 $\mathrm{m} / \mathrm{s}$ (winter), and $\mathrm{B} 10-\mathrm{B} 12$ with values located close to $4.6 \mathrm{~m} / \mathrm{s}$ (winter). On the opposite side, the points B7 and B8 can be considered, where the wind speeds do not exceed $3.1 \mathrm{~m} / \mathrm{s}$ during the total time or $3.8 \mathrm{~m} / \mathrm{s}$ in winter. The monthly distribution of the wind speed for the most relevant points is presented in Figure 9(b), from which the influence of the winter season can be observed. First of all, it can be noticed that the differences between the points are very small, the point $\mathrm{B} 2$ presenting slightly higher values during January-March $(5.6 \mathrm{~m} / \mathrm{s})$ or for SeptemberOctober interval $(4.8 \mathrm{~m} / \mathrm{s})$. During the summer time, in the reference points, wind speeds in the interval $2.3-4.2 \mathrm{~m} / \mathrm{s}$ can be noticed, with some energetic peaks during June and September. Regarding the structure of the wind, in Figure 9(c), it is represented the histogram corresponding to the point B2. As it can be observed, the wind occurrences from the interval $3-6 \mathrm{~m} / \mathrm{s}$ are the most important, while the values higher than $12 \mathrm{~m} / \mathrm{s}$ are almost close to zero. During the winter time, the wind conditions located under $3 \mathrm{~m} / \mathrm{s}$ seem to be insignificant reported to the total wind budget.

A similar analysis is performed in Figure 10 in the Caspian Sea area. The seasonal mean values (Figure 10(a)) indicate that the point $\mathrm{C} 6$ seems to have the most important wind resources indicating a maximum of $6.6 \mathrm{~m} / \mathrm{s}$ during winter, this point being also indicated by the NCEP dataset. Other important points can be considered: $\mathrm{C} 1$ with $5.3 \mathrm{~m} / \mathrm{s}$ and $6.6 \mathrm{~m} / \mathrm{s}$ (total-winter time), C2 $\rightarrow 5.1 \mathrm{~m} / \mathrm{s}-6.3 \mathrm{~m} / \mathrm{s}$ and $\mathrm{C} 12 \rightarrow 5.3 \mathrm{~m} / \mathrm{s}-6.5 \mathrm{~m} / \mathrm{s}$. The point $\mathrm{C} 9$ appears to be the less energetic one, since the wind conditions do not exceed $4.4 \mathrm{~m} / \mathrm{s}$, even during the winter, this aspect being also indicated by the NCEP data. Regarding the monthly distribution, the seasonal pattern of the wind conditions can be observed when a maximum of $7.4 \mathrm{~m} / \mathrm{s}$ appears during February, while the point $\mathrm{C} 2$ has considerably lower values for the interval October-December. During the summer time, the selected points have wind speed values between 3 and $5 \mathrm{~m} / \mathrm{s}$, lower values being registered in May. The wind histogram is indicated in Figure 10(c) for the point C6, where during the total time a similar distribution can be observed as in the case of the point B2, while during the winter season an energetic peak for the interval 6-9 $\mathrm{m} / \mathrm{s}$ is reported.

Table 3 presents a statistical analysis of the wind conditions considering the same reference points as in the case presented in Table 2 (NCEP data). In general, it can be observed that the values indicated by the satellite measurements are significantly lower than those given by the model, both during the total and the winter time. From the analysis of the $95 \%$ it can be observed that the Black Sea points present values in the range $6.89-9.37 \mathrm{~m} / \mathrm{s}$ (total time) and $8.16-$ $10.23 \mathrm{~m} / \mathrm{s}$ (in winter) compared to the Caspian Sea, where during the winter time the values are close to $11 \mathrm{~m} / \mathrm{s}$. For the extreme values, a maximum of $22.4 \mathrm{~m} / \mathrm{s}$ is indicated by the point $\mathrm{C} 6$, being followed by $\mathrm{B} 2$ with $15.9 \mathrm{~m} / \mathrm{s}$, while on the opposite side the point B7 presents a minimum of $13 \mathrm{~m} / \mathrm{s}$. During the winter time, the power density takes values in the range $66-161 \mathrm{~W} / \mathrm{m}^{2}$ for the B points, compared to 212 $245 \mathrm{~W} / \mathrm{m}^{2}$ in the Caspian basin.

\section{Conclusions}

In the present work a comprehensive picture of the wind energy potential in the Black and the Caspian Seas is provided 


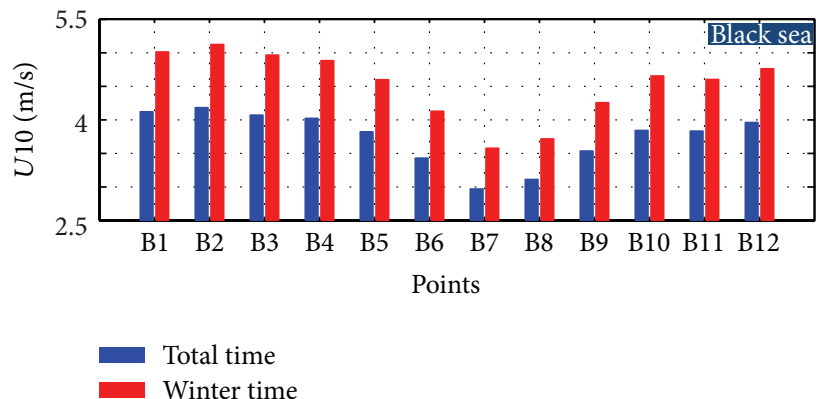

(a)

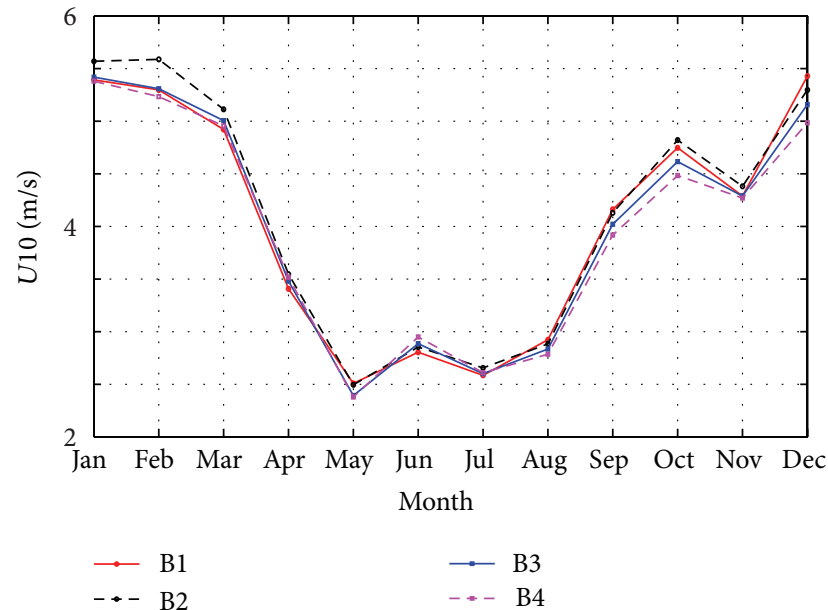

(b)

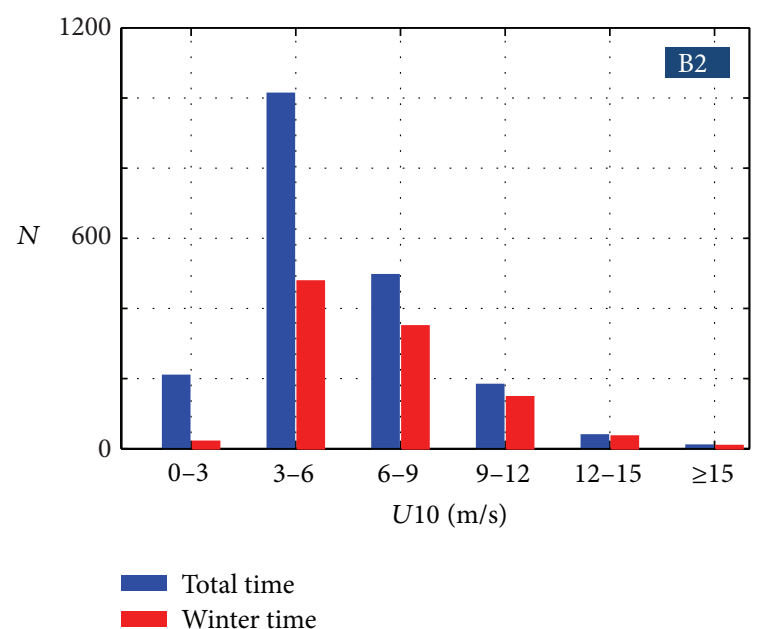

(c)

FIGURE 9: Evaluation of the wind conditions in the Black Sea based on satellite measurements. The results are reported to the time interval 2010-2014, for (a) mean wind speed for the total and winter time, respectively, (b) the monthly evolution of the U10 parameter in the points $\mathrm{B} 1, \mathrm{~B} 2, \mathrm{~B} 3$, and B4, and (c) wind speed histogram corresponding to the point B2.

TABLE 3: Statistical analysis of the satellite measurements, corresponding to the total time (TT) and winter time (WT), respectively. The results cover the five-year time interval 2010-2014.

\begin{tabular}{|c|c|c|c|c|c|c|c|c|c|}
\hline \multirow{3}{*}{ Results } & \multirow{3}{*}{ Time interval } & \multicolumn{8}{|c|}{ Point } \\
\hline & & \multicolumn{4}{|c|}{ Black Sea } & \multicolumn{4}{|c|}{ Caspian Sea } \\
\hline & & $\mathrm{B} 2$ & B5 & B7 & $\mathrm{B} 10$ & $\mathrm{C} 3$ & C6 & $\mathrm{C} 7$ & $\mathrm{C} 11$ \\
\hline \multirow{2}{*}{$U 10(\mathrm{~m} / \mathrm{s})$} & TT & 4.18 & 3.82 & 2.96 & 3.84 & 4.74 & 5.32 & 4.98 & 4.712 \\
\hline & WT & 5.12 & 4.59 & 3.57 & 4.65 & 5.83 & 6.62 & 6.12 & 5.735 \\
\hline \multirow{2}{*}{$95 \%(\mathrm{~m} / \mathrm{s})$} & TT & 9.37 & 8.41 & 6.89 & 8.43 & 9.32 & 10.81 & 10.17 & 9.642 \\
\hline & WT & 10.23 & 9.17 & 8.16 & 9.56 & 11.29 & 11.96 & 11.75 & 11.37 \\
\hline \multirow{2}{*}{ Extreme (m/s) } & TT & 15.88 & 15.4 & 12.99 & 15.06 & 16.35 & 22.43 & 21.76 & 20.24 \\
\hline & WT & 15.88 & 15.4 & 12.99 & 15.06 & 16.35 & 22.43 & 21.76 & 20.24 \\
\hline \multirow{2}{*}{ Power density $\left(\mathrm{W} / \mathrm{m}^{2}\right)$} & $\mathrm{TT}$ & 109 & 80.52 & 44.43 & 80.72 & 133.7 & 190.4 & 160.4 & 139.1 \\
\hline & WT & 160.9 & 115.3 & 66.01 & 119.3 & 217.1 & 296.1 & 245.3 & 211.7 \\
\hline
\end{tabular}

from a meteorological point of view. The analysis is based both on the reanalysis data coming from the National Centers for Environmental Prediction (NCEP), which cover a 10-year interval (1999-2008), and also throughout some measured data (both in situ and remotely sensed).

By dividing each target area into four rectangular domains, it was possible to identify in each basin the most promising locations from the point of view of the wind energy potential. Regarding the Black Sea region, it was found that the windiest locations seem to be situated in the northwestern part of the sea, especially in the vicinity of the point B2, which is located close to Ukraine. For the Caspian region, the points C5 and C6 (Kazakhstan) stand out with significant values, especially during the winter time. The less energetic areas were found to be in the southern part of the Black Sea, while in the Caspian Sea lower values of the wind speed and power 


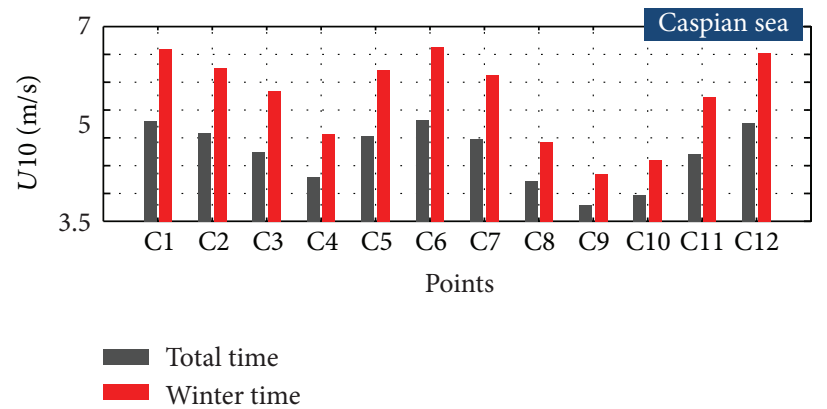

(a)

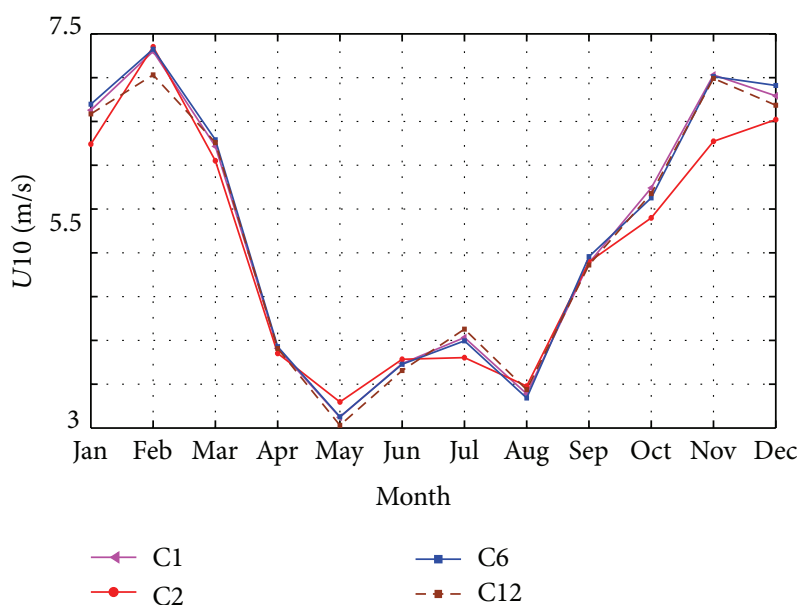

(b)

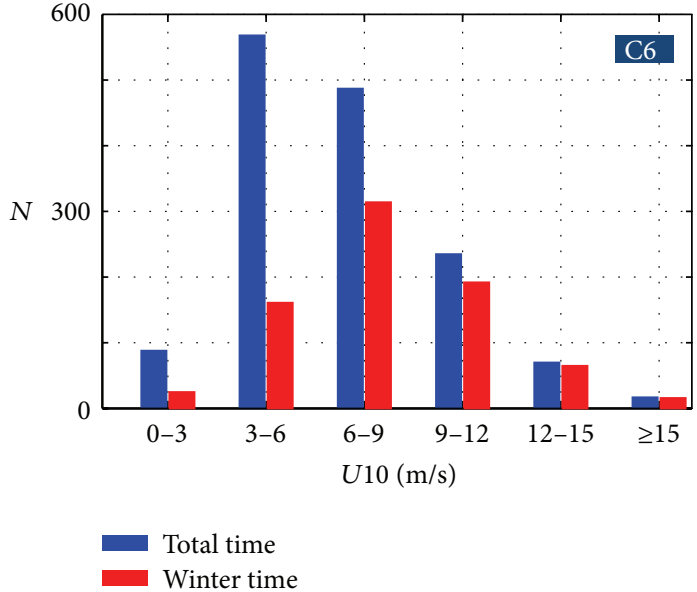

(c)

FIGURE 10: Evaluation of the wind conditions in the Caspian Sea based on satellite measurements. The results are reported to the time interval 2010-2014, for (a) mean wind speed for the total and winter time, respectively, (b) monthly evolution of the U10 parameter in the points C1, C2, C6, and C12, and (c) wind speed histogram corresponding to the point C6.

density were reported in the points located in the southern and southwestern parts of the basin.

These results are also confirmed by the satellite measurements, which indicate, with a good accuracy, the most or the less energetic points from the two areas targeted, with the mention that the values are usually below the ones provided by the NCEP model. If we take into account that the most energetic area presents also relevant wave energy resources, it can be expected in the near future to be developed hybrid wind-waves farms, which might also play an important role in the coastal protection (see, e.g., Zanopol et al. $[18,19])$. This especially takes into account the fact that many of the coastal areas targeted are subjected to intense processes of coastal erosion (Diaconu and Rusu [20]). Regarding the diurnal/nocturnal distributions of the wind conditions, it was found that these conditions are different for each geographical region, while on a local scale the most important variations occur in the directional patterns of the wind.

Based both on the NCEP data and on the satellite measurements, it is shown that the two enclosed seas targeted in the present work can provide suitable conditions for the implementation of the offshore wind parks. On the other hand, if we take a step back looking at the big picture, it can be assumed that since the Caspian Sea is an area rich in oil, there are few chances at this moment to see a renewable project in this area. As regards the Black Sea, although the strongest wind conditions were noticed near the coastlines of Ukraine, considering the current geopolitical climate, it might be rather unrealistic to make plans there for an offshore farm. In this context, it can be concluded that one of the most interesting regions is located in the vicinity of the Romanian coast, nearshore that has a good wind potential as also the capacity to develop a renewable project in the offshore areas.

\section{Conflict of Interests}

The authors declare that there is no conflict of interests regarding the publication of this paper.

\section{Acknowledgments}

This work was supported by a grant of the Romanian Ministry of National Education, CNCS-UEFISCDI PN-IIID-PCE-2012-4-0089 (project DAMWAVE). The work of the first author has been funded by the Sectoral Operational Programme Human Resources Development 2007-2013 of the Ministry of European Funds through the Financial 
Agreement POSDRU/159/1.5/S/132397. The wind dataset corresponding to the Ukrainian coastal environment of the Black Sea was kindly provided by the Ukrainian Research Hydrometeorological Institute. The altimeter products were produced by Ssalto/Duacs and distributed by Aviso with support from Cnes.

\section{References}

[1] A. Rotaru, "Some geo-aspects of the Black Sea basin," in Proceedings of the 3rd International Conference on Environmental and Geological Science and Engineering, pp. 169-174, 2010.

[2] E. Rusu, F. Onea, and R. Toderascu, "Dynamics of the environmental matrix in the Black Sea as reflected by recent measurements and simulations with numerical models," in The Black Sea: Dynamics, Ecology and Conservation, Nova Science Publishers, New York, NY, USA, 2011.

[3] W. Alpers, A. Ivanov, and J. Horstmann, "Observations of Bora events over the Adriatic Sea and Black Sea by spaceborne synthetic aperture radar," Monthly Weather Review, vol. 137, no. 3, pp. 1150-1161, 2009.

[4] E. Rusu and F. Onea, "Evaluation of the wind and wave energy along the Caspian Sea," Energy, vol. 50, no. 1, pp. 1-14, 2013.

[5] F. Stolberg, O. Borysova, I. Mitrofanov, V. Barannik, and P. Eghtesadi, Caspian Sea, GIWA Regional Assessment 23, University of Kalmar, Kalmar, Sweden, 2006.

[6] V. Mamaev, Seas Around Europe. Europe's Biodiversity-Biogeographical Regions and Seas, European Environment Agency, 2002.

[7] F. Onea and E. Rusu, "Wind energy assessments along the Black Sea basin," Meteorological Applications, vol. 21, no. 2, pp. 316329, 2014.

[8] E. Rusu, "Assessment of the wave energy conversion patterns in various coastal environments," Energies, vol. 7, no. 6, pp. 40024018, 2014, Proceedings of the 1st International e-Conference on Energies.

[9] L. Rusu and F. Onea, "Assessment of the performances of various wave energy converters along the European continental coasts," Energy, vol. 82, pp. 889-904, 2015.

[10] E. Kalnay, M. Kanamitsu, R. Kistler et al., "The NCEP/NCAR 40-year reanalysis project," Bulletin of the American Meteorological Society, vol. 77, no. 3, pp. 437-471, 1996.

[11] S. Saha, S. Moorthi, H.-L. Pan et al., "The NCEP climate forecast system reanalysis," Bulletin of the American Meteorological Society, vol. 91, no. 8, pp. 1015-1057, 2010.

[12] B. H. Fiedler and A. S. Adams, "A subgrid parameterization for wind turbines in weather prediction models with an application to wind resource limits," Advances in Meteorology, vol. 2014, Article ID 696202, 6 pages, 2014.

[13] A. S. Ahmed Shata and R. Hanitsch, "Evaluation of wind energy potential and electricity generation on the coast of Mediterranean Sea in Egypt," Renewable Energy, vol. 31, no. 8, pp. 1183-1202, 2006.

[14] F. Onea and E. Rusu, "An evaluation of the wind energy in the North-West of the Black Sea," International Journal of Green Energy, vol. 11, no. 5, pp. 465-487, 2014.

[15] R. Kerimov, Z. Ismailova, and N. R. Rahmanov, "Modeling of wind power producing in Caspian Sea conditions," International Journal on Technical and Physical Problems of Engineering, vol. 15, no. 5, pp. 136-142, 2013.
[16] N. Rahmanov, R. Kerimov, E. Gurbanov et al., "Assessing the wind potential of Caspian Sea region for covering demand in neighboring countries and reducing of carbon emission," in Proceedings of the 2nd International Symposium on Energy Challenges \& Mechanics, Aberdeen, UK, August 2014.

[17] AVISO, 2015, http://www.aviso.altimetry.fr/en/home.html.

[18] A. Zanopol, F. Onea, and E. Rusu, "Coastal impact assessment of a generic wave farm operating in the Romanian nearshore," Energy, vol. 72, pp. 652-670, 2014.

[19] A. Zanopol, F. Onea, and E. Rusu, "Evaluation of the coastal influence of a generic wave farm operating in the Romanian nearshore," Journal of Environmental Protection and Ecology, vol. 15, no. 2, pp. 597-605, 2014.

[20] S. Diaconu and E. Rusu, "The environmental impact of a wave dragon array operating in the Black Sea," The Scientific World Journal, vol. 2013, Article ID 498013, 20 pages, 2013. 

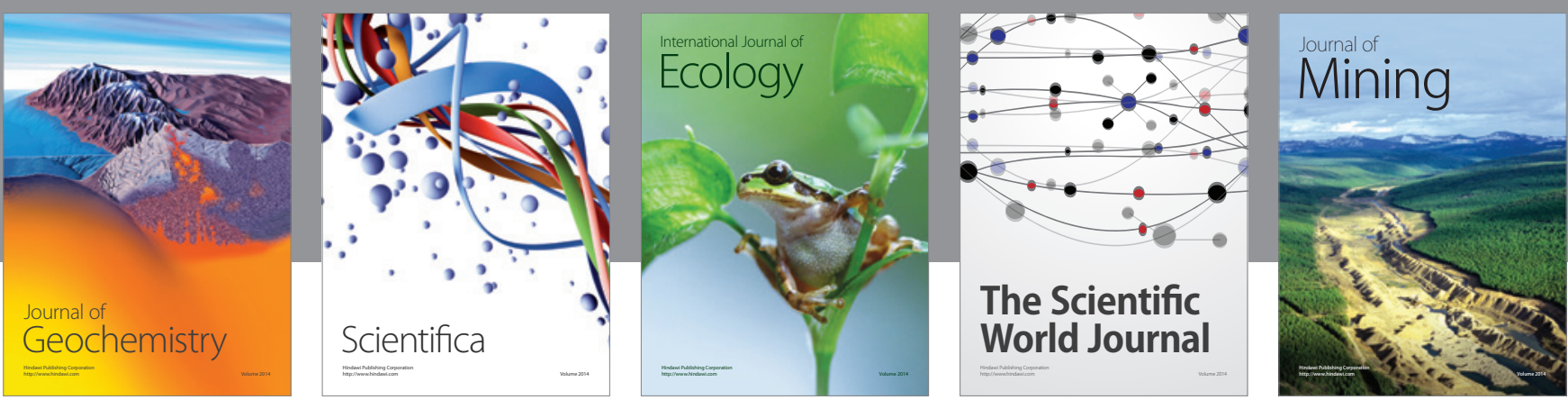

The Scientific World Journal
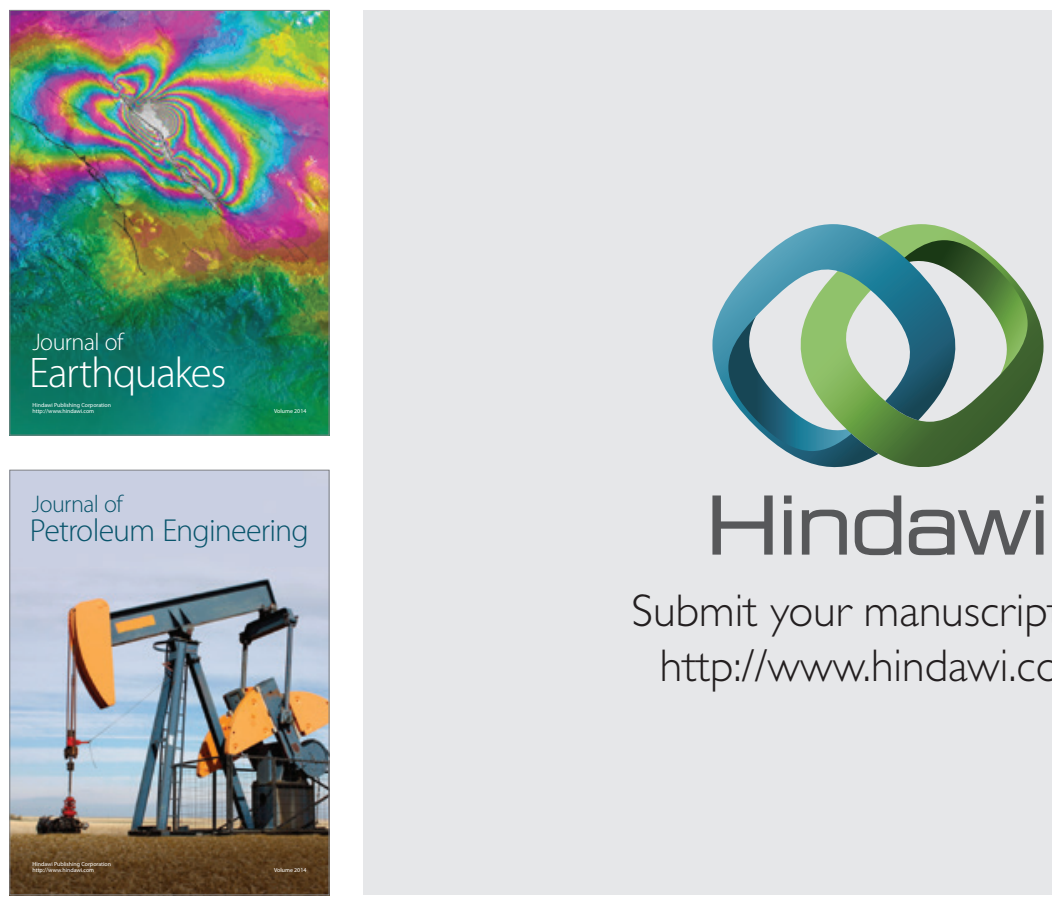

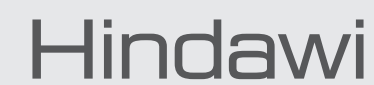

Submit your manuscripts at

http://www.hindawi.com
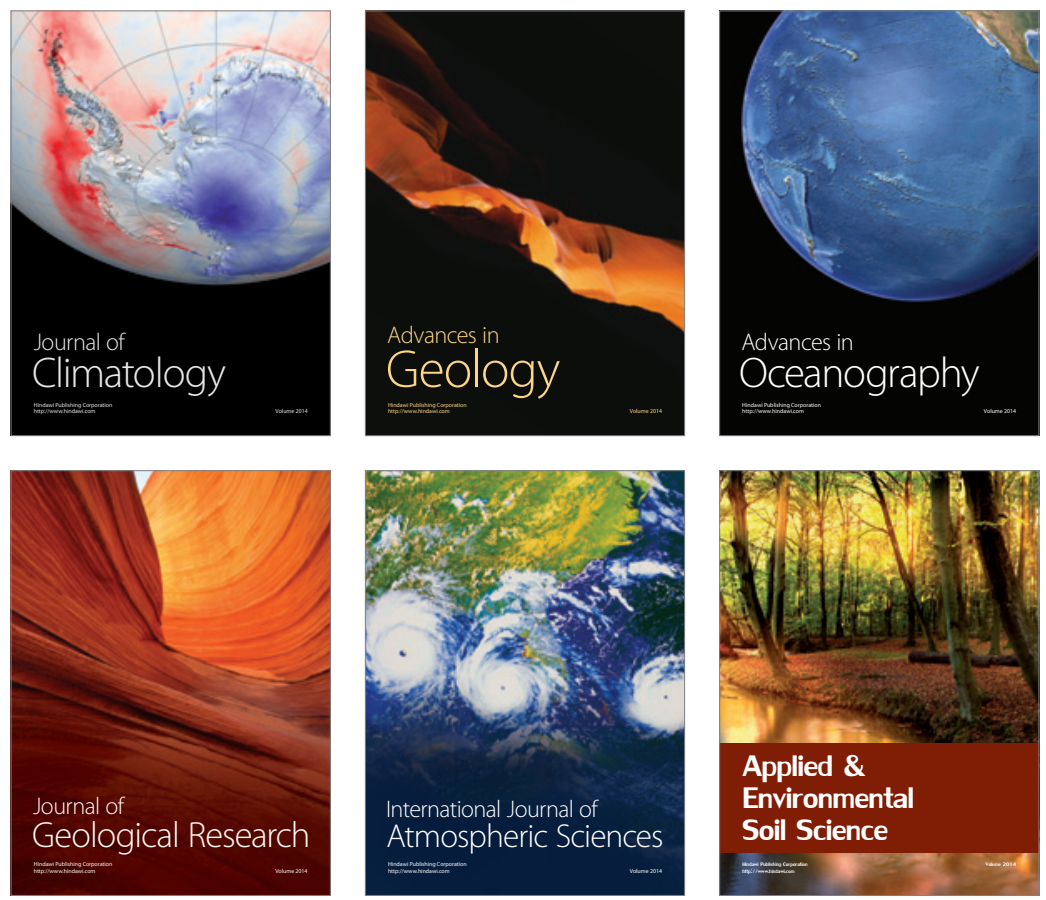
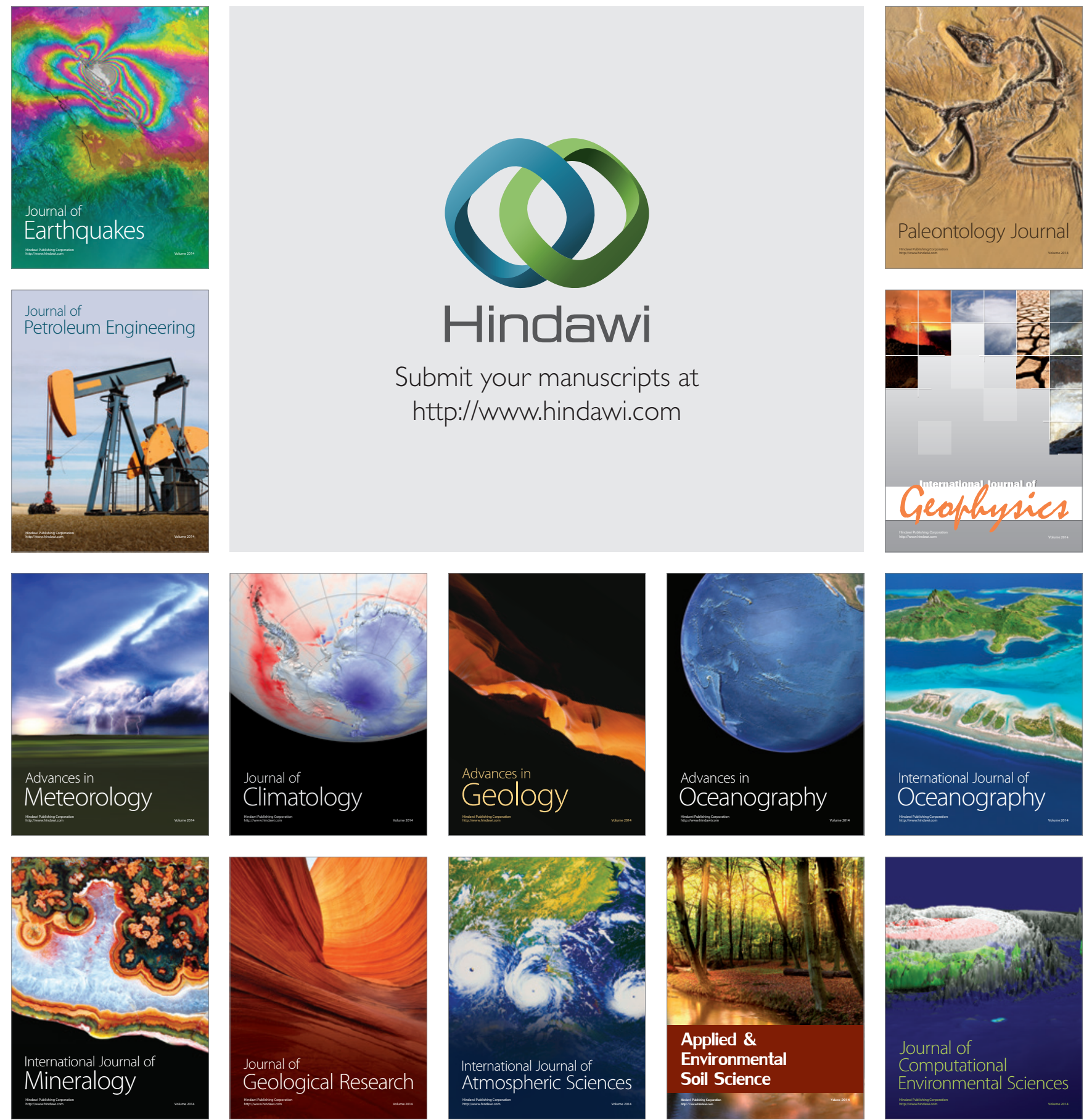